\title{
The Medicago truncatula IEF Gene Is Crucial for the Progression of Bacterial Infection During Symbiosis
}

\author{
Szilárd Kovács, ${ }^{1}$ Ernő Kiss, ${ }^{2}$ Sándor Jenei, ${ }^{1}$ Erzsébet Fehér-Juhász, ${ }^{2}$ Attila Kereszt, ${ }^{1}$ \\ and Gabriella Endre ${ }^{1, \dagger}$ \\ ${ }^{1}$ Biological Research Centre, Institute of Plant Biology, Eötvös Loránd Research Network (ELKH), Szeged, Hungary \\ ${ }^{2}$ Biological Research Centre, Institute of Genetics, Eötvös Loránd Research Network (ELKH), Szeged, Hungary
}

Accepted 15 February 2022.

\begin{abstract}
Legumes are able to meet their nitrogen need by establishing nitrogen-fixing symbiosis with rhizobia. Nitrogen fixation is performed by rhizobia, which has been converted to bacteroids, in newly formed organs, the root nodules. In the model legume $\mathrm{Med}$ icago truncatula, nodule cells are invaded by rhizobia through transcellular tubular structures called infection threads (ITs) that are initiated at the root hairs. Here, we describe a novel $M$. truncatula early symbiotic mutant identified as infection-related epidermal factor (ief), in which the formation of ITs is blocked in the root hair cells and only nodule primordia are formed. We show that the function of MtIEF is crucial for the bacterial infection in the root epidermis but not required for the nodule organogenesis. The $I E F$ gene that appears to have been recruited for a symbiotic function after the duplication of a flower-specific gene is activated by the ERN1-branch of the Nod factor signal transduction pathway and independent of the NIN activity. The expression of MtIEF is induced transiently in the root epidermal cells by the rhizobium partner or Nod factors. Although its expression was not detectable at later stages of symbiosis, complementation experiments indicate that MtIEF is also required for the proper invasion of the nodule cells by rhizobia. The gene encodes an intracellular protein of unknown function possessing a coiled-coil motif and a plant-specific DUF761 domain. The IEF protein interacts with RPG, another symbiotic protein essential for normal IT development, suggesting that combined action of these proteins plays a role in nodule infection.
\end{abstract}

Keywords: bacteria-plant symbiosis, genetics and gene regulation, infection thread, Medicago truncatula, molecular signaling, nodule development, Rhizobium-legume symbiosis, symbiotic mutant

${ }^{\dagger}$ Corresponding author: G. Endre; endre.gabriella@brc.hu

Funding: This study was supported by the bilateral Hungarian-French collaborative project LEGUMICS (NFÜ grant TÉT_10-1-2011-0397 and ANR grant 2010-INTI3-1602-01); GINOP-2.2.1-15-2017-00051 Proteomill, Frontline Research project KKP129924; and K120122 grant of the Hungarian National Office for Research, Development and Innovation (NKFIH). Additional support was provided by the Balzan research grant to É. Kondorosi. S. Kovács has been a recipient of the Young Researcher Fellowship previously from the Hungarian Academy of Sciences, currently from the Eötvös Loránd Research Network (ELKH).

*The $\boldsymbol{e}$-Xtra logo stands for "electronic extra" and indicates that supplementary figures and supplementary tables are published online.

The author(s) declare no conflict of interest.

(c) (1) $(-)$ Copyright $\odot 2022$ The Author(s). This is an open access article distributed under the CC BY-NC-ND 4.0 International license.
Legumes can overcome the limitation of nitrogen availability in the soil by establishing symbiotic interaction with bacteria, collectively referred to as rhizobia, that are capable of reducing atmospheric nitrogen $\left(\mathrm{N}_{2}\right)$ to ammonium that plants can use. The nitrogen fixation takes place in the root nodules, which are de novo formed specific organs (Gibson et al. 2008). In the nodules, most plant cells are colonized by thousands of metabolically specialized rhizobia, called bacteroids, which are separated from the cytoplasm of the host cell by a plant-derived peribacteroid membrane and form symbiosomes (Roth and Stacey 1989). This niche provides adequate environmental conditions to meet the special requirements of nitrogen fixation such as very low oxygen concentration in the environment of the oxygen-sensitive nitrogenase enzyme complex and, at the same time, continuous flow of free oxygen to bacterial terminal oxidases to support the high energy demand for nitrogen reduction (Rutten and Poole 2019).

During nodulation, two interconnected processes, nodule formation and rhizobial infection, take place, and failure of either developmental program blocks the progression of the other one. Nodule development is initiated when plant membrane receptors (Fliegmann and Bono 2015) recognize bacterial lipo-chitooligosaccharide signal molecules, called Nod factors, which are produced after the induction of the bacterial nod genes by flavonoids present in root exudates upon nitrogen starvation (Liu and Murray 2016). The signal is relayed through the so-called common symbiosis signal transduction pathway, including another receptor-kinase, ion channels, nucleoporins, and a calcium/calmodulin-dependent protein kinase (Oldroyd et al. 2011) to the transcription regulators such as IPD3/ IPD3L, NSP1/NSP2, NIN, ERN1/ERN2, NF-Y, and DELLA proteins (Horváth et al. 2011; Jin et al. 2016, 2018; Kaló et al. 2005; Laporte et al. 2014; Middleton et al. 2007; Schauser et al. 1999; Smit et al. 2005) that govern the reprogramming of cells required for the development of the new nodule tissues and the infection structures that facilitate rhizobial colonization. In Medicago spp., cell division is reactivated in cortex, endodermis, and pericycle cells to form the nodule tissues. The meristem, which continuously produces the cells of the growing nodule, originates from the third cortical cell layer, while infected and noninfected cells at the base of the nodule are formed from inner cortical cells and the endodermis or pericycle, respectively (Xiao et al. 2014). These newly formed cells are invaded by rhizobia through transcellular tubular structures called infection threads (ITs), which are plasma membrane invaginations with cell wall deposition and showing polar tip growth. The infection process is initiated after the attachment of rhizobia to the growing root hairs, where the local production of Nod factors leads to the continuous reorientation of the root hair tip growth, resulting in the entrapment of bacteria and the formation of a so-called closed infection chamber (Fournier et al. 2015; Murray 2011). In the infection 
chamber, rhizobial cell division establishes a microcolony, a cell wall structural remodeling takes place, and an IT is initiated. The polar growth of ITs in the root hairs and in the underlying cortical cells follows the migrating nucleus, which is connected first to the infection chamber and then to the IT tip by an endoplasmic reticulum-rich cytoplasmic bridge (Fournier et al. 2008; Gage 2004). Rhizobia divide in the continuously growing ITs and are eventually released from the ramifying ITs into the cytoplasm of differentiating nodule cells via an endocytosis-like process. Bacteria enwrapped in plant-derived membranes form organelle-like structures called symbiosomes, where they differentiate into nitrogen-fixing bacteroids (Ivanov et al. 2012).

Genetic analysis has identified a number of plant genes required for bacterial invasion (i.e., the initiation and progression of ITs). Mutations in the Nod factor-responsive transcription factors NIN, ERN1, and NF-YA of Medicago truncatula result in the early arrest of infection without the formation of microcolonies (nin) or ITs (ernl or $n f-y a)$ (Cerri et al. 2016; Laloum et al. 2014; Laporte et al. 2014; Marsh et al. 2007; Middleton et al. 2007). Transcriptome analysis of root hairs from these mutants revealed that more than half of the genes induced by rhizobia is regulated by NIN-including NF-YA and its targets-whereas ERN1 controls a smaller and partially overlapping set of genes that acts independently to control infection (Liu et al. 2019a). A number of NINregulated genes or functions have been shown to be important for rhizobial infection; for example, rhizobial infection receptor-like kinase genes (RINRKs) with unknown ligands (Li et al. 2019) are required for full induction of NIN as well as for IT development but not for nodule organogenesis, while the Lotus exopolysaccharide receptor 3 monitors the structure of the bacterial exopolysaccharide (EPS) and prevents the entry of rhizobia producing truncated EPS into epidermal cells (Kawaharada et al. 2015). Lack of the nodulation pectate lyase protein (NPL) secreted to the infection chamber (Xie et al. 2012) and the membrane-localized cystathionine- $\beta$-synthase-like 1 protein (CBS1) (Sinharoy et al. 2016) leads to the formation of an increased number of microcolonies as well as defects in IT initiation and formation (Liu et al. $2019 b$ ). Mutation in another member of the NIN regulon, RPG (rhizobium-directed polar growth), results in incomplete root hair curling and entrapment of bacteria, as well as the formation of abnormally thick and slowly progressing ITs (Arrighi et al. 2008). The importance of polar growth in IT progression is underlined by the fact that mutations affecting several components of the WAVE/SCAR-APR2/3 complex required for actin nucleation and rearrangement such as NAP, PIR, ARPC1, and the symbiosis-specific SCARN/API result in rhizobial infection and IT defects (Gavrin et al. 2020; Hossain et al. 2012; Miyahara et al. 2010; Qiu et al. 2015; Yokota et al. 2009). Polar growth also requires the transport of secretory vesicles to the cell membrane and their fusion at the growing tip, a process helped by the exocyst complex (Mei and Guo 2018). A rhizobium-induced member of the complex, EXO70H4, is also required for the early stages of IT development (Liu et al. 2019b). Absence of an E3 ubiquitin ligase (LIN/CERBERUS) results in aberrant development of ITs that are arrested after very limited progression into the infected root hair cells (Kiss et al. 2009; Yano et al. 2009), indicating the importance of posttranslational modifications such as protein ubiquitination. A mutant defective in the VAPYRIN (VPY) protein of unknown function shows epidermal penetration defects and aborted arbuscule formation as well as abnormal rhizobial infection threads upon fungal (Pumplin et al. 2010) and bacterial (Murray 2011) inoculation, respectively. Three of the above-described essential proteins-VPY, LIN, and EXO70H4 - form a multiprotein complex after rhizobial inoculation, which is localized to small puncta in the vicinity of the nucleus and close to the membrane in a position facing attached rhizobium during root hair curling and infection chamber development and, subsequently, at the growing tip of ITs (Liu et al. 2019b). The predicted function of this complex (e.g., recruiting the exocyst complex to the tip of IT) remains, however, to be elucidated.

Here, we report on the identification and characterization of a novel symbiotic gene, IEF (infection-related epidermal factor), encoding a protein with domain of unknown function (DUF761) that is required for successful rhizobial infection in $M$. truncatula. The mutant plant showed early abortion of IT development and only nodule primordia were detected on inoculated roots. MtIEF possesses a distinctive expression profile and is dependent on the Nod factor signal transduction pathway and the activity of the MtERN1 transcription factor.

\section{RESULTS}

\section{Rhizobial infection is arrested}

\section{in a new $M$. truncatula symbiotic mutant.}

To find potentially novel symbiotic mutants in the Tnt1/ MERE1 insertional mutant collection generated in the $M$. truncatula Jemalong 2HA background (Iantcheva et al. 2009; Rakocevic et al. 2009; Tadege et al. 2008) 30 T1 plants from each line were grown in medium with limited nitrogen and inoculated with the wild-type (WT) rhizobium partner Sinorhizobium medicae strain WSM419. This screen led to the identification of line F9451V, in which few individuals showed an impaired symbiotic nitrogen fixation $\left(\mathrm{Fix}^{-}\right)$phenotype with retarded growth, yellowish leaves, and small white or brownish bumps or nodule primordia 6 weeks after inoculation, while their siblings were WT-looking green plants with elongated pink nitrogen-fixing nodules (Supplementary Fig. S1A and B). The incidence of mutant individuals in the line F9451V and the fact that self-pollinated progeny of the Fix ${ }^{-}$ individuals resulted in only $\mathrm{Fix}^{-}$plants indicated a recessive inheritance of the mutation. To determine at what stage the symbiotic process is affected in the mutants, plants were inoculated with S. medicae strain WSM419 carrying a constitutively expressed gusA gene to follow the progression of nodule development and bacterial infection. M. truncatula 2HA was used as WT control to compare the symbiotic phenotype at each time point from root hair curling through the initiation and growth of the ITs toward the developing nodule primordia where they ramified and released bacteria (Fig. 1A to C). In the mutants, root hair curling and the formation of infection foci were similar to the WT (Fig. 1D) at 2 days postinoculation (dpi) but, subsequently, the infection process was blocked (Fig. 1E and F). At 3 dpi, bacteria remained mostly entrapped in root hair curls, forming microcolonies (Fig. 1G, stage I). Occasionally, ITs were initiated (Fig. 1G, stage II) but their growth was usually terminated prematurely; only few ITs progressed toward the base of the root hair cells (Fig. 1G, stage III) and none of them grew beyond the epidermal cell layer. Even at later time points, ITs did not progress further, confirming that the phenotype was not due to their delayed development but to the complete arrest of IT growth in the epidermis of the mutant plants (Fig. 1H). Despite the early abortion of IT development, cell proliferation started in the cortex and led to the formation of nodule primordium that did not develop further (Fig. 1F). In addition to the early aborted infection process in the symbiosis, no other phenotype was detected in any other organ of this mutant and mutant plants grew normally in nitrogen-supplemented medium or soil.

\section{Inactivation of the MtIEF gene is responsible for the symbiotic phenotype.}

A great advantage of insertional mutants is the possibility to identify the flanking sequence tags (FSTs) of the insertions and follow their inheritance and potential cosegregation with the mutant phenotype, thereby identifying the responsible gene. FST sequences for both Tnt1 and MERE1 insertions of M. truncatula 
line F9451V and other mutants of the collection were determined by next-generation sequencing. Nine FSTs were determined for line F9451V; five of them corresponded to coding sequences, out of which four located in exons (three were hit by the Tnt1 retrotransposon and one by MtMERE1) and one in the $3^{\prime}$ untranslated region (Supplementary Table S1). To analyze the cosegregation of the FSTs with the mutant phenotype, we designed primers distinguishing the WT and mutant alleles (Supplementary Table S2) for the four genes (Medtrlg087720, Medtr2g031750, Medtr4g040410, and Medtr5g026290) carrying insertion in their exons. These primers were used in PCR assays to determine the genotypes of the individuals by detecting the presence or absence of WT and mutant alleles of the tested genes. In total, 37 individuals of the population segregating the mutant phenotype (self-pollinated progeny of $\mathrm{BC} 1$ originating from the F9451V $\times 2 \mathrm{HA}$ back-cross) were evaluated for symbiotic phenotype. Nine of them were Fix ${ }^{-}$, confirming the monogenic recessive nature of the mutation. All nine Fix ${ }^{-}$mutants but none of the WT individuals were homozygous for the presence
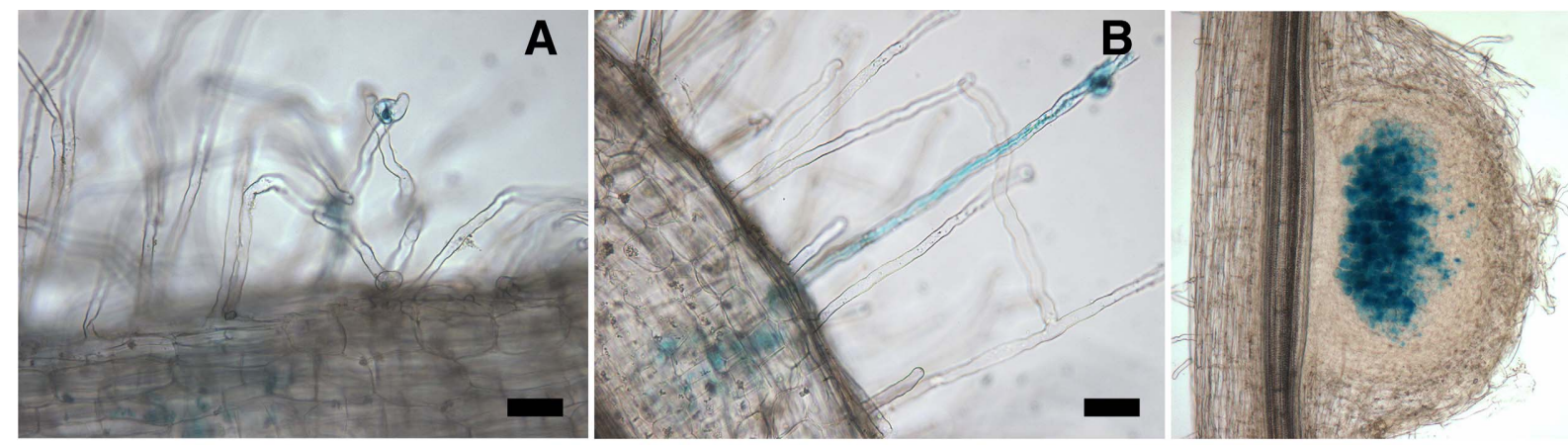

C
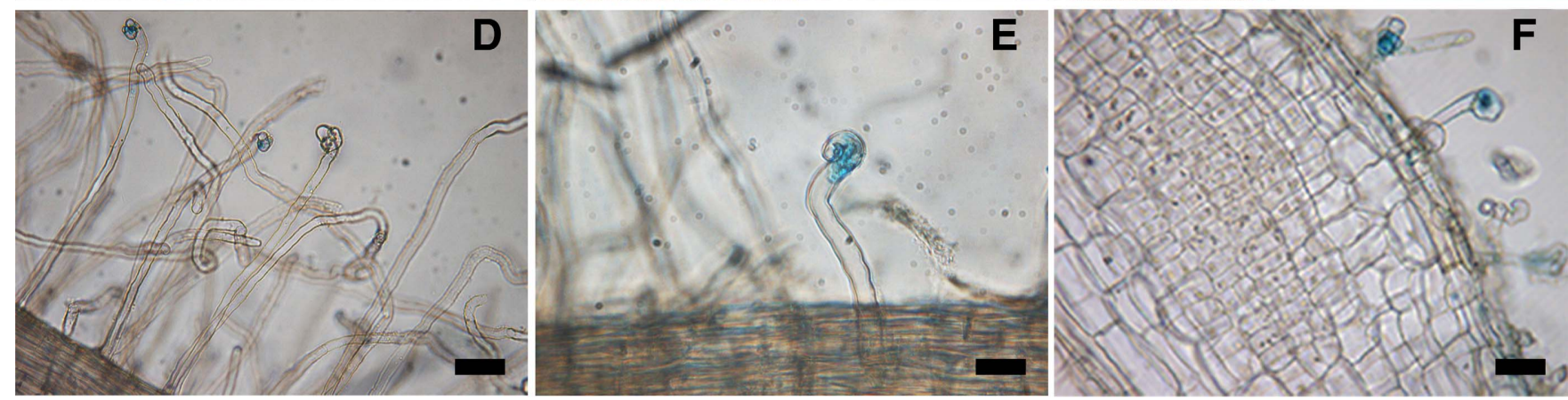

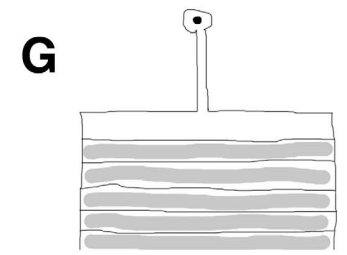

STAGE I

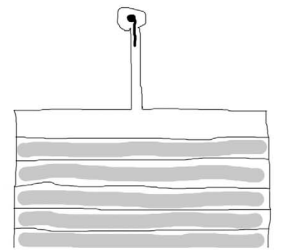

STAGE II

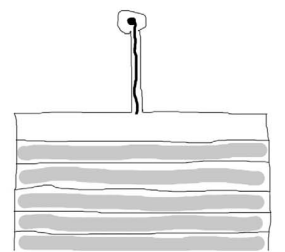

STAGE III

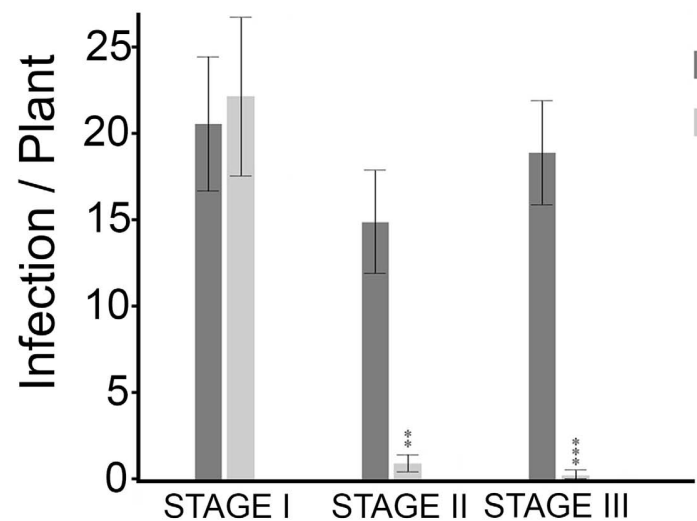

$2 \mathrm{HA}$

ief-1

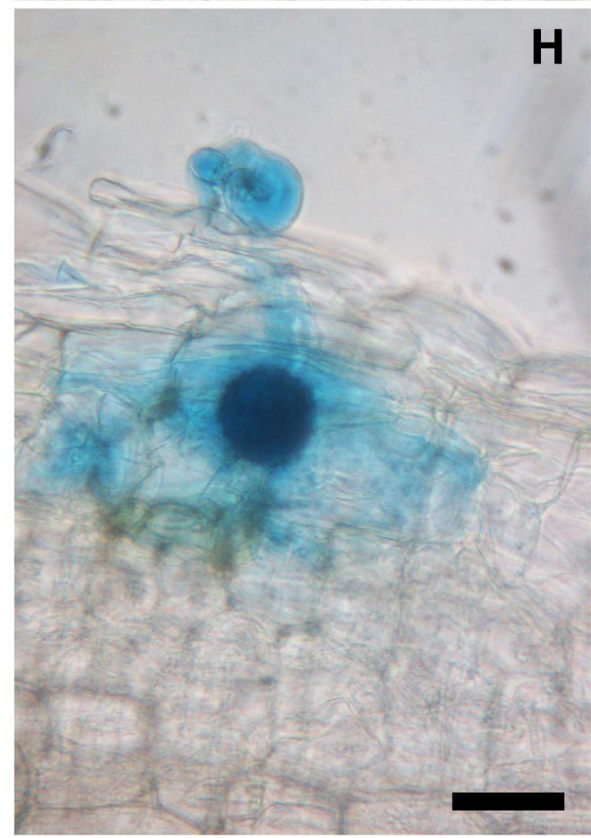

Fig. 1. Early infection phenotype is detected on the symbiotic mutant of line F9451V with Sinorhizobium medicae WSM419 visualized by blue $\beta$-glucuronidase staining. In the wild-type (WT) 2HA plants, the steps of bacterial invasion-that is, A, root hair curling at 2 days postinoculation (dpi); B, infection thread (IT) formation at $3 \mathrm{dpi}$; and $\mathbf{C}$, nodule invasion at $4 \mathrm{dpi}-$ can be observed. In the F9451V mutant, whereas $\mathbf{D}$, root hair curling at 2 dpi looked normal, only $\mathbf{E}$, delayed and abnormal IT formation and $\mathbf{F}$, no invasion of nodule primordia could be detected at 6 dpi. G, At 3 dpi, there were already definite differences in the progress of ITs, as shown by the average numbers of curled root hairs (stage I), initiated ITs (stage II), and ITs fully progressed in the epidermis (stage III) counted in WT and mutant plants in the susceptible zone of the roots. Mean \pm standard error from $n=8$ for both WT and mutant plants. Asterisks in the bar charts indicate a significant level by paired-samples $t$ test: ** and *** indicate $P \leq 0.01$ and 0.001 , respectively. H, Later, at 12 dpi, bacteria are still visibly stuck and multiplied in the epidermis. Representative microscopic images are from whole roots (A, B, D, and E) and 70- $\mu \mathrm{m}$ nodule sections $(\mathrm{C}, \mathrm{F}$, and $\mathrm{H})$. Scale bars $=50 \mu \mathrm{m}$. 
of the Tnt1 insertion in the Medtrlg087720 gene (Supplementary Fig. S1C), suggesting that the mutation in Medtrlg087720 was responsible for the early arrest of ITs in the root hairs.

In line with the early infection phenotype caused by the mutation, this gene was named $I E F$. Publicly accessible expression data also suggest induction at early time points of symbiosis by both Nod factor and rhizobia but only in those experiments where root hair tissues were collected and analyzed (Breakspear et al. 2014; Damiani et al. 2016). However, in these experiments, the differences showed a low level of significance due to low expression and relatively high standard deviation. This suggested that, due to its temporally and spatially limited expression, sample collection and preparation may have a large effect on MtIEF expression data.

In order to confirm the symbiotic function of the MtIEF gene, genetic complementation experiments were carried out using the Agrobacterium rhizogenes-mediated hairy root transformation system. We have designed and generated three constructs in which the expression of the MtIEF gene was driven by the constitutive cauliflower mosaic virus 35S (p35S) or Lotus japonicus ubiquitin (pLjUB) promoters, or by the 1.9-kbp fragment of the native MtIEF promoter (pMtIEF). Transgenic roots developed on the F9451V mutants were inoculated with the $S$. medicae strain WSM419 expressing constitutively the lacZ marker gene and the symbiotic phenotype was assessed 3 weeks postinoculation. Although the control mutant plants transformed with the empty vector formed only bumps (i.e., uninfected nodule primordia) (Fig. 2A to C), pinkish, elongated nodules with infected cells appeared on the roots generated with any of the three MtIEF constructs (Fig. 2D to L), proving that the mutation in the MtIEF gene was responsible for the early symbiotic phenotype. Although the initial block of bacterial infection in ief- 1 could be overcome by introducing the WT MtIEF gene driven by any of the promoters used, nodules on the complemented roots did not show proper zonation of indeterminate nodules and contained a reduced number of invaded symbiotic cells compared with WT nodules. When the native promoter-driven MtIEF gene was used for complementation, more infected cells were observed than in the nodules developed after transformation with the constructs regulated by constitutive promoters. This observation suggests that, in addition to its fundamental role in the early bacterial infection in the root hairs, the fine-tuned expression of MtIEF is also necessary for the proper invasion of the nodule cells by rhizobia.

\section{The MtIEF gene codes for a legume-specific intracellular protein of unknown function.}

The MtIEF (Medtr1g087720) gene is composed of a single exon and encodes a protein of 253 amino acids. The Tnt1 retrotransposon was inserted at nucleotide position 253 of the MtIEF coding region in the ief- 1 allele in line F9451V (Fig. 3A). Based on domain and structure predictions, the MtIEF protein carries a plant-specific DUF761 domain with unknown function at the C-terminal end and a coiled-coiled motif in the middle part (Fig. 3B). No transmembrane domain or secretory signal sequences were predicted indicating the intracellular localization of the protein, which was further supported by a nuclear export signal (NES) motif predicted at the C-terminal end of the MtIEF protein (Fig. 2B) and confirmed in subsequent experiments. Similarity search at the protein level identified a homologous sequence in $M$. truncatula that carries the DUF761 domain in the same position but does not have a predicted coiled-coil motif. The two proteins share an overall $38 \%$ identity at the amino acid level, and the MtIEF homolog (encoded by the Medtr7g109300 gene) was named MtIEF-LIKE (MtIEFL) protein. Both MtIEF and MtIEFL genes showed flower-specific expression according to their expression profiles, available in the Medicago Gene Atlas database (Benedito et al. 2008; He et al. 2009), but MtIEF was also slightly induced by rhizobial infection and Nod factor treatment. Phylogenetic analysis of IEF and IEF-LIKE proteins from legume and nonlegume plants grouped the sequences into two clades (Fig. 3C). Although the IEF clade consists only of legume proteins, the IEF-LIKE clade contains both legume and nonlegume sequences, including homologs in di- and monocotyledonous species, indicating that the protein might have a general function in the florescence. This observation indicates that a gene duplication event occurred in the ancestors of leguminous plant lineages and that the new copy has obtained a symbiosis-specific activity that is essential for IT initiation and development.

We expressed the MtIEF gene fused to the green fluorescent protein (GFP) coding sequence driven by the p35S promoter to investigate the localization of the protein in transgenic hairy roots of the ief-1 mutant. Although this construct was able to complement the early symbiotic phenotype of the mutant (data not shown), no fluorescence signal could be detected in the cells of the transgenic roots. Thus, the level of the fusion protein was sufficient to fulfill the symbiotic function of MtIEF but was not high or persistent enough to be detected in this system. Because the subcellular localization of the MtIEF protein could not be determined in its natural environment, it was further investigated by another transient expression method in a heterologous system. The p35S::GFP::MtIEF construct and the DsRED gene expressed independently from the Arabidopsis ubiquitin10 promoter (pAtUb10) were coinfiltrated into Nicotiana benthamiana leaves (Supplementary Fig. S2). The GFP signal corresponding to the localization of MtIEF was detected in both the cytoplasm and the nucleus, though with a slightly higher intensity in the cytoplasm than in the nucleus. Red signal of the control DsRED fluorescent protein was evenly distributed in the cytosol and the nucleus. The overlay image of the green and red signals confirmed the colocalization of MtIEF with the independently expressed DsRED and strengthened the more abundant cytosolic and weaker nuclear localization of the MtIEF protein.

\section{Nodule organogenesis does not require MtIEF.}

As was described above, the symbiotic phenotype of the ief- 1 mutant was characterized by an early arrest of the ITs in the root hairs while cortical cell division and the nodule primordium formation were initiated but subsequently blocked. To test whether the function of MtIEF is required only for bacterial invasion but not for the parallel process of nodule organogenesis, we tried to induce spontaneous nodules on the roots of the WT and mutant plants by the ectopic expression of the truncated autoactive form of the $\mathrm{Ca}^{2+} /$ calmodulin-dependent protein kinase (CCaMK/ DMI3), DMI $3^{1-311}$ (Gleason et al. 2006). Plants with transgenic roots were grown with limited nitrogen supply for 6 to 7 weeks in the absence of rhizobia, and spontaneous nodules could be detected on the transgenic roots of both the ief- 1 mutant and WT plants (Fig. 4A to D), indicating that MtIEF is not essential for the nodule organogenesis.

We also monitored the activity of the symbiosis reporter construct $\mathrm{p} E N O D 11$-gusA by introducing it into the roots of ief- 1 and WT plants via $A$. rhizogenes-mediated transformation. At 3 and 6 dpi with $S$. medicae strain WSM419, the $\beta$-glucuronidase activity was similar in the transgenic mutant and the WT plants in both the dividing cortical cells and nodule primordia (Fig. 4E to $\mathrm{H}$ ). This result indicated that the MtIEF protein was not essential for the Nod factor-dependent induction of the MtENOD11 promoter.

\section{$M t I E F$ is induced exclusively in the epidermal cells following bacterial inoculation and Nod factor treatment and acts downstream of MtERN1.}

The spatiotemporal expression pattern of $M t I E F$ was analyzed by introducing the $\beta$-glucuronidase (GUS) reporter gene fused to the 1.9-kbp pMtIEF promoter fragment used in the complementation 

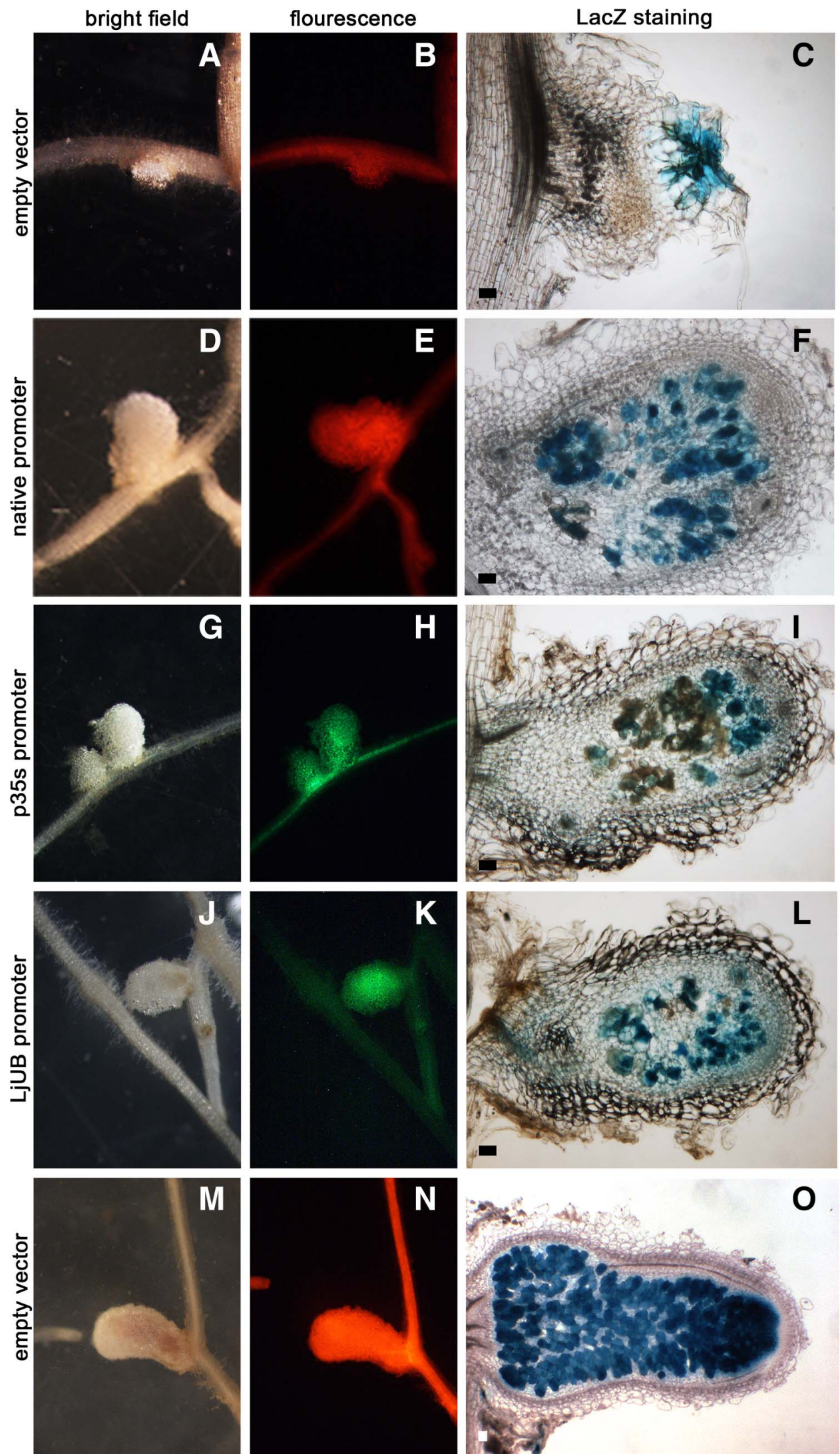

Fig. 2. Functional complementation of the F9451V mutant with the wild-type (WT) MtIEF gene driven by different promoters. A to C, The symbiotic phenotype of the hairy roots of the mutant transformed with the empty vector served as mutant control. None of the transgenic roots developed elongated nodules ( 0 nodule on 26 roots). Restoration of nodule invasion by rhizobia constitutively expressing the lac $Z$ gene could be achieved by expressing the MtIEF gene in hairy roots under the control of the $\mathbf{D}$ to $\mathbf{F}$, native pMtIEF (23 nodules on 60 roots); $\mathbf{G}$ to $\mathbf{I}$, p35S (29 nodules on 45 roots); or $\mathbf{J}$ to $\mathbf{L}$, pLjUB (6 nodules on 12 roots) promoters. M to $\mathbf{O}$, As a comparison, WT nodules formed on the transgenic roots of $2 \mathrm{HA}$ plants $(n=10)$ are shown. Pictures were taken at 30 to 35 days postinoculation from whole roots (A, B, D, E, G, H, J, K, M, and N) and 80- $\mu$ m nodule sections (C, F, I, L, and O). Scale bars $=50 \mu \mathrm{m}$. 
assays into WT plants by A. rhizogenes transformation. Noninoculated hairy roots showed some blue GUS staining in the vascular tissues (Fig. 5A). To confirm the Nod factor-inducible expression of MtIEF, Nod factor-containing sterile exudate of $S$. medicae strain WSM419 was applied on the transgenic roots. After $24 \mathrm{~h}$, the strong blue staining in epidermal cells indicated the induction of MtIEF by Nod factors (Fig. 5B). Similarly, when transgenic roots were inoculated with $S$. medicae strain WSM419, the blue staining appeared in the epidermal cells (Fig. 5C to E) but was restricted to the area of bacterial invasion indicated by the curled root hairs. After the formation of the primordium, GUS activity dropped dramatically and was subsequently not detectable in the developing (Fig. 5F and $\mathrm{G}$ ) and mature (Fig. $5 \mathrm{H}$ ) nodules. Occasionally (in $9 \%$ of the nodules), faint blue GUS staining was observed at a random location near the base of the nodule, the relevance of which is not yet known. Thus, the results of the promoter activity staining experiments clearly showed that the expression of the MtIEF gene is, indeed, under tight spatial and temporal control, as suggested by publicly available expression data. The detected promoter activity
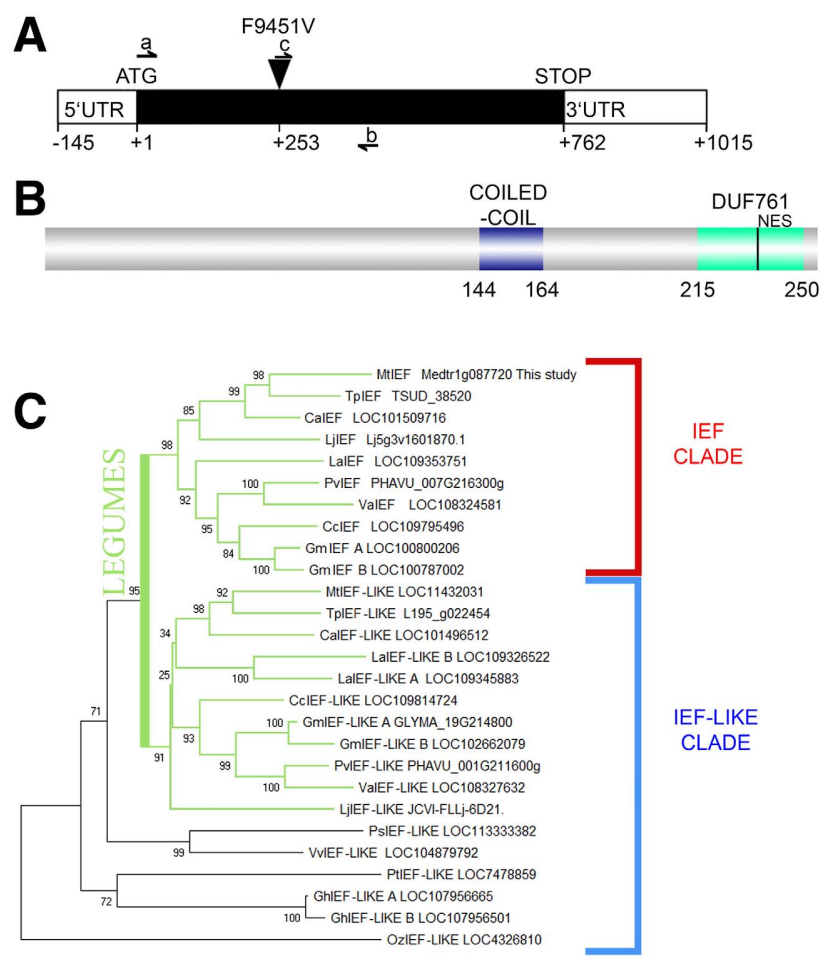

Fig. 3. MtIEF encodes a protein carrying a DUF761 domain and a coiledcoil region and belongs to a subclade of a legume-specific protein family. A, Schematic presentations of the genomic structure of the identified gene Medtrlg087720, named MtIEF. The position of the Tntl insertion in the ief-1 allele is marked by an arrowhead. Primers used to distinguish the wild-type (gene-specific oligos a and b, PCR product of $405 \mathrm{bp}$ ) and mutant (Tnt1-specific oligo $c$ and oligo $b$, PCR product of $352 \mathrm{bp}$ ) alleles are indicated by short half-arrows. UTR $=$ untranslated region. $\mathbf{B}$, The predicted small MtIEF protein contains a DUF761 domain (green box) and a conserved coiled-coil region (blue box) and has a nuclear export signal (NES) sequence. C, Phylogenetic analysis of the MtIEF protein and identified homologous representatives showed the presence of the infection-related epidermal factor (IEF)LIKE clade in addition to the IEF clade. Protein sequences were obtained from NCBI via searching for homologs of MtIEF in several legume and nonlegume species. Sequences were aligned using ClustalW and the phylogenetic tree was built using the MEGA-X software by applying the neighbor-joining method using a Poisson substitution model and the bootstrap value set at 2,000. Abbreviations: $\mathrm{Mt}=$ Medicago truncatula, $\mathrm{Tp}=$ Trifolium pratense, $\mathrm{Ca}=$ Cicer arientum, $\mathrm{La}=$ Lupinus angustifolius, $\mathrm{Cc}=$ Cajanus cajan, $\mathrm{Gm}=$ Glycine $\max , \mathrm{Pv}=$ Phaseolus vulgaris, $\mathrm{Va}=$ Vigna angularis, $\mathrm{Lj}=$ Lotus japonicus, $\mathrm{Ps}=$ Papaver somniferum, $\mathrm{Vv}=$ Vitis vinifera, $\mathrm{Pt}=$ Populus trichocarpa, $\mathrm{Gh}=$ Gossypium hirsutum, and $\mathrm{Oz}=$ Oryza sativa . clearly coincided with and was limited to those epidermal cells where the MtIEF function was necessary for the development of ITs.

The activity of the MtIEF promoter was analyzed in several early symbiotic plant mutants (Supplementary Table S3) to position MtIEF in the hierarchy of symbiotic genes. We transformed the $\mathrm{p} M t I E F:: G U S$ construct into $M$. truncatula mutants defective in different elements of the Nod factor signal transduction pathway (lyk3, dmi2, dmi3, ipd3, nsp2, ernl, and nin). The inducibility of the promoter was analyzed after $24 \mathrm{~h}$ of treatment with the Nod factor containing exudate when the activity of the pMtIEFGUS reporter was strong in the WT roots (Fig. 6A). The epidermal-specific induction of the MtIEF promoter could not be detected in the lyk3, nsp2, dmi2, dmi3, ipd3, and ern1 mutants (Fig. 6B to G), though occasional GUS activity (three cases in 23 roots) could be observed in the $d m i 3$ mutant close to the root tip but not in the growing root hair (i.e., nodulation-competent zone). In contrast, the activity in the nin mutant was similar to the one in the WT line (Fig. 6H). These data indicated that $L Y K 3, N S P 2, N O R K, D M I 3, I P D 3$, and ERN1 were required for the activity of $M t I E F$, which placed the function of MtIEF gene downstream of the MtERN1 gene.

\section{MtIEF interacts with symbiotic protein MtRPG essential for IT development in the epidermis.}

To test whether MtIEF shows interaction with any of the proteins that act at the early stages of symbiosis and are expressed in the root epidermis where MtIEF is active, yeast two-hybrid experiments were carried out. Interaction of MtIEF was studied with the intracellular kinase domain of receptor kinases MtDMI2 (DMI2-IC), MtNFP (NFP-IC), and MtLYK3 (LYK3-IC), as well as with the MtIPD3, MtDMI3, MtRPG, and MtLIN proteins and with those derivatives of transcription factors MtNSP1 and MtNSP2 that do not show autoactivity (Hirsch et al. 2009). In this screen, MtIEF exhibited interaction only with MtRPG (Fig. 7A; Supplementary Fig. S3). This interaction was supported with all possible control combinations that confirmed that neither MtIEF nor MtRPG showed transcriptional activity and was not prone to form homodimers in this system (Fig. 7A).

To validate the interaction between the MtIEF and MtRPG proteins in another in vivo experimental system, the proteins were transiently expressed in epidermal cells of $N$. benthamiana leaves to detect bimolecular fluorescence complementation (BiFC). The subcellular localization of MtRPG was already defined in this system as showing a nuclear signal and significantly reduced signal within the cytoplasm (Arrighi et al. 2008), which overlapped with the pattern of MtIEF that showed a slightly higher intensity in the cytoplasm than in the nucleus. In the BiFC experiments, $N$. benthamiana leaves were cotransformed with $A$. tumefaciens strains carrying different combinations of MtIEF and MtRPG genes fused to $\mathrm{N}$ - or C-terminal parts of the split yellow fluorescent protein $(Y F P)$ gene. As positive controls, the early symbiotic transcription factors MtNSP1 and MtNSP2 that show colocalization and strong interaction in the nucleus (Hirsch et al. 2009) were also introduced into $N$. benthamiana leaves. The YFP signal detected upon infiltration of RPG-nYFP and IEF-cYFP confirmed the interaction between MtIEF and MtRPG (Fig. 7B). The yellow fluorescent signal was predominantly detected in the cytosol, which was more characteristic for the localization of the MtIEF-GFP fusion protein than for that of MtRPG.

\section{DISCUSSION}

Here, we report on a new $M$. truncatula symbiotic gene, IEF, which is required for the infection process at the early stage of nitrogen-fixing symbiosis. MtIEF was identified with the help of the Tntl retrotransposon-tagged mutant line F9451V, in which 
the insertion in the coding region of Medtrlg087720 abolished its function and resulted in an arrest of the initiation and growth of ITs in the root hairs. This gene encodes a short protein where only a domain of unknown function (DUF761) and a coiled-coil region could be identified; thus, the gene was named based on the early infection arrest phenotype of its mutant and its characteristic inducible expression in the epidermis of the infected root as $I E F$.

The symbiotic phenotype of the mutant ief- 1 has revealed that its function is indispensable for the early symbiotic events, which are known to be governed by the Nod factor signaling pathway in legumes. The quick arrest of ITs in the root hair and the cessation of the nodule organogenesis indicated that the action of the MtIEF gene was needed somewhere after the $D M I$ genes, at the level of MtIPD3 or downstream of it. At this early stage, a symbiotic plant gene may play a role in the epidermal events of the rhizobial infection, the organogenesis of the nodules, or in both interrelated processes. In order to better define the role of $I E F$ in the early symbiotic events, we aimed to place its function in the hierarchy of the other elements in the Nod factor signal transduction pathway. Introducing the autoactive DMI $3^{1-311}$ into the plants resulted in the induction of spontaneous nodules on the transgenic roots of the ief-1 mutant similar to that on the WT plants, indicating that $M t I E F$ is not required for the nodule organogenesis program downstream of MtDMI3. In addition, the activity of the ENOD11 promoter in the ief- 1 mutant roots was also induced upon rhizobial inoculation to the same extent as in the WT plants; that is, the induction of this symbiosis marker gene was not dependent on $I E F$. The expression pattern of MtIEF was investigated with the help of the GUS reporter gene fused to the 1.9-kbp pMtIEF promoter and by analyzing public data from a number of transcriptome studies (Breakspear et al. 2014; Damiani et al. 2016; Roux et al. 2014). Treatment of the transgenic roots with Nod factor-containing sterile exudates for $24 \mathrm{~h}$ triggered the activity of the $1.9-\mathrm{kbp}$ pMtIEF in all epidermal cells in the symbiosissusceptible region of the roots. This induction required the activity of the early Nod factor signal transduction pathway elements
(LYK3, NORK/SYMRK, and DMI3) and associated transcription factors (IPD3, NSP2, and ERN1) but the presence of WT NIN was not needed. When roots were infected with rhizobia, promoter activity was detected in the infected root hairs and in a restricted region of surrounding epidermal cells 2 and 3 dpi, which rapidly decreased by 4 dpi and was undetectable in any other cells and at any later time points of nodulation. This expression spatially and temporally restricted to the site crucial for the development of ITs during rhizobial infection was supported by in silico analysis of RNA-sequencing data obtained after lasercapture microdissection of nodule tissues (Roux et al. 2014), where no reads were obtained from any region of the nodule. This expression pattern of MtIEF, however, is in contrast to other infection-related genes of Medicago such as MtVPY, MtRPG, $M t L I N, M t E X O 7 O H 4$, or MtCBS1, which are all expressed in the infection zone of nitrogen-fixing nodules as well. Moreover, most of those genes that are induced by Nod factors and are known to be indispensable for IT initiation or development ( $R P G, C B S 1$, and NPL) in Medicago are regulated by NIN (Liu et al. 2019a); thus, IEF is the first known essential effector in the NINindependent part of the ERN1 regulon. However, the distinctive expression pattern indicated that a fine-tuned expression of MtIEF is required for its proper function, which may depend on other transcription factors in addition to ERN1.

The WT MtIEF gene could complement the early infection defect of ief-1; that is, the arrest of the ITs in the epidermal cells of the transgenic roots was rescued by the MtIEF gene driven by either the constitutive promoters ( $\mathrm{pCaMV} 35 \mathrm{~S}$ and $\mathrm{pLjUB}$ ) or the native 1.9-kbp pMtIEF promoter, and the bacterial infection could proceed further into the developing nodules. Bacteria were subsequently released in the host plant cells and nitrogen-fixing pink nodules appeared. On the other hand, improper zonation of the indeterminate nodules was found and the number of nodule cells invaded by bacteria varied depending on the promoter used but was always lower than in the WT nodules. This observation suggests that, despite the fact that gene expression could not be detected, the IEF protein might be needed for later functions of
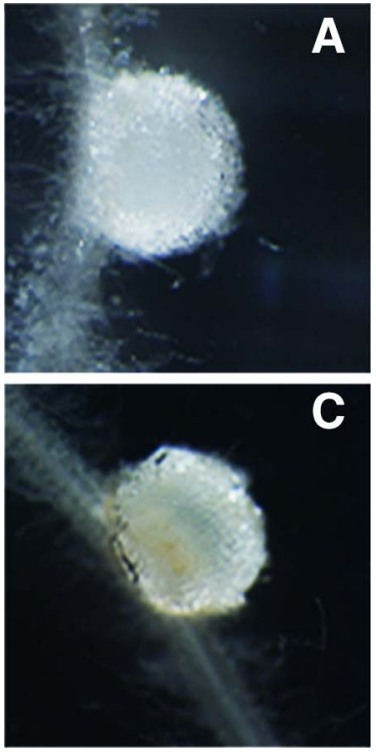
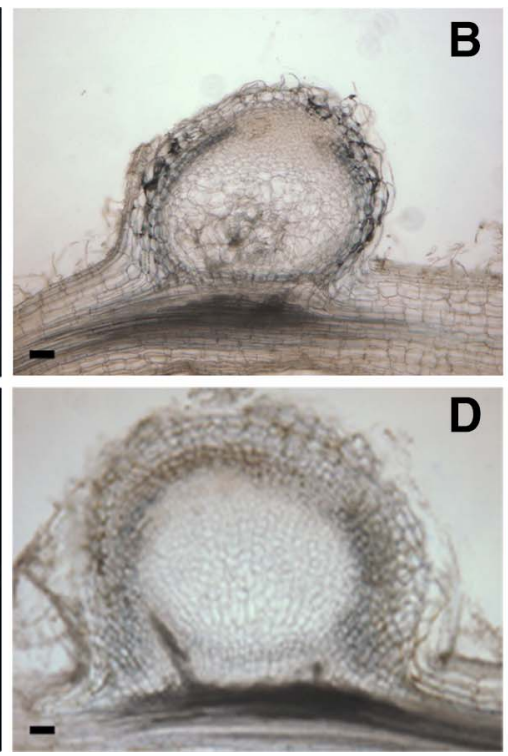
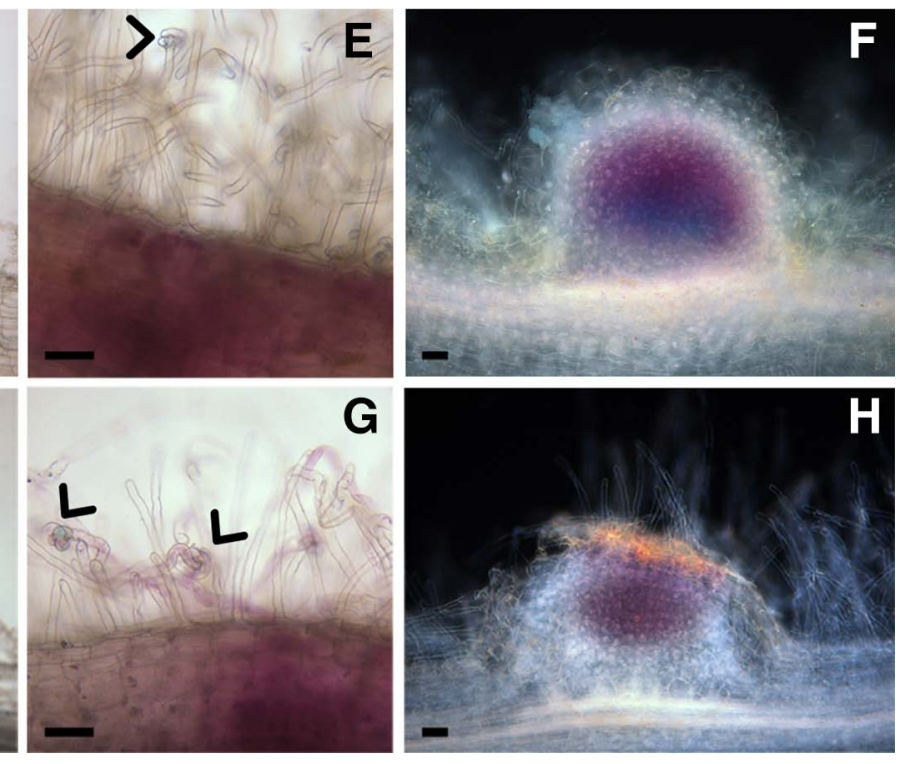

Fig. 4. Nodule organogenesis and early nodulin expression do not require infection-related epidermal factor (IEF). Spontaneous nodule formation was induced by expressing the autoactive DMI $3^{1-311}$ protein in transgenic roots and evaluated 6 to 7 weeks posttransformation. A and $\mathbf{B}$, Wild-type (WT) 2HA plants formed four nodules/transgenic root $(n=11$ plants), while $\mathbf{C}$ and $\mathbf{D}$, the ief- 1 mutants developed an average of six nodules/transgenic root ( $n=26$ plants). Activation of the pENOD11 promoter (driving the gusA reporter gene) by rhizobia was tested in transgenic roots of $\mathbf{E}$ and $\mathbf{F}$, the WT and $\mathbf{G}$ and $\mathbf{H}$, mutant plants at 3 days postinoculation (dpi) (E and G), 5 dpi (F), and 6 dpi (H). Roots were stained for both pENOD11 activity (magenta) and the presence of the bacteria (blue) by $\beta$-glucuronidase-LacZ double staining. Pictures were taken from whole roots (A, C, E, F, G, and $\mathrm{H}$ ) and from 70- $\mu \mathrm{m}$ sections (B and D). Symbols: > indicates rhizobia in curled root hairs. The average number of nodule primordia in WT plants at 5 dpi was 14.66 ( \pm standard error $[\mathrm{SE}]=2.39$ ) while that in the ief- 1 mutant at 6 dpi was $12.37( \pm \mathrm{SE}=0.94)$. Scale bars $=50 \mu \mathrm{m}$. 
ITs such as proper growing or ramifying of the ITs or the release of bacteria into the plant cells. It is known that production of Nod factors by rhizobia is needed during the later stages of the symbiosis as well. Thus, the bacterial signal molecules and activity of the plant signaling pathway not only launch the early responses in the plant roots but also needed, for example, in the developing nodules where bacteria are released from the ITs into the nodule cells. This was nicely demonstrated by the different symbiotic phenotypes of the mutants of the MtDMI2 gene. In case of the complete absence of the DMI2 receptor gene, mutants are characterized by no root hair curling or cortical cell division at all (Catoira et al. 2000) whereas, in DMI2 RNAi-silenced roots, the first symbiotic responses could be evoked, nodules formed, and bacterial infection proceeded toward them but bacteria were not released into the nodule cells (Limpens et al. 2005). The functional complementation of several other early symbiotic mutants such as nin and ernl showed similar features to ief; that is, the introduced WT gene rescued the original arrest of the symbiosis but resulted in nodules that were not fully matured (Middleton et al. 2007; Vernié et al. 2015). These data further support the idea that the function of important elements of Nod factor signaling in the early symbiotic responses is essential at later stages of the symbiosis as well.

Though the function of the MtIEF protein is required in later steps of the symbiosis as well, its expression was not detectable, indicating that a very fine-tuned regulation of the gene is needed
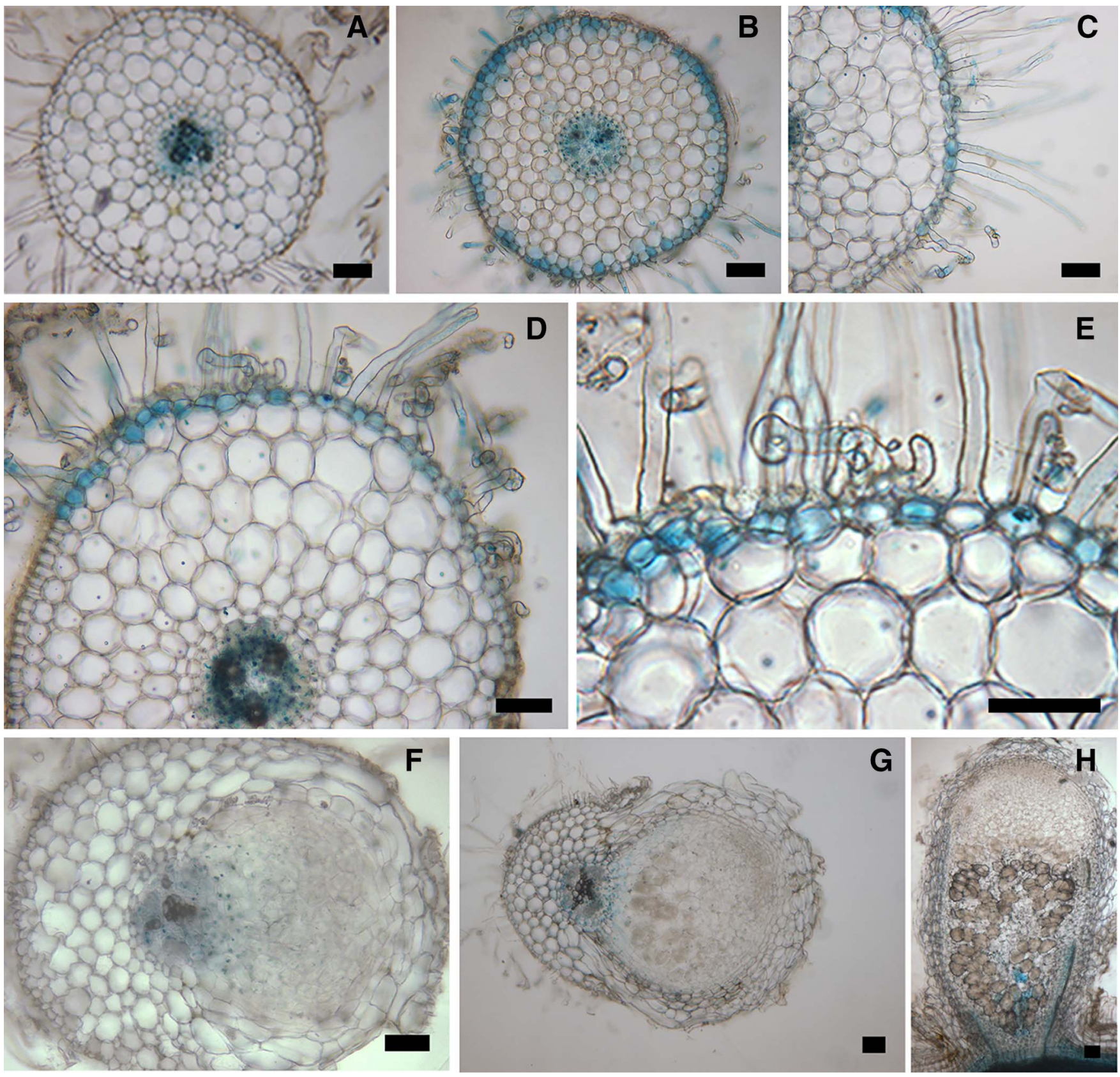

Fig. 5. Spatiotemporal analysis of the MtIEF expression. $\beta$-Glucuronidase (GUS) activity in $2 \mathrm{HA}$ plants carrying a 1.9-kbp fragment of the pMtIEF promoter fused to the GUS reporter was detected in sections from the susceptible zone of hairy roots: A, uninoculated roots; B, roots treated with Nod factor containing exudate for $24 \mathrm{~h}$; and roots after inoculation with Sinorhizobium medicae WSM419 at C, 2 days postinoculation (dpi) and D and E, 3 dpi. Activity was detected in sections from nodule primordia or nodules at $\mathbf{F}, 5 \mathrm{dpi}$; $\mathbf{G}, 6 \mathrm{dpi}$; and $\mathbf{H}, 14$ dpi. Blue GUS staining of varying intensity was detected in the vascular tissues of each section. A clear induction of the pMtIEF promoter was observed exclusively in the root epidermis early after the Nod factor treatment (B) and upon S. medicae inoculation (C to E), where curled root hairs were visible. Scale bars $=50 \mu \mathrm{m}$. 
and the 1.9-kbp promoter fragment might not contain all of the necessary regulatory elements. Such remote cis-regulatory sequences are not without precedents even for symbiotic genes: for example, a conserved region with putative cytokinin response elements required for NIN expression in the inner cell layers of the root and for nodule primordium formation is located approximately $18 \mathrm{kbp}$ upstream of the MtNIN coding region (J. Liu et al. 2019). The other putative regulatory elements, however, must allow very restricted expression in space, time, and strength considering the lack of sequence reads from the microdissected nodule zones and the incomplete invasion of nodules formed after the complementation achieved by the constitutive expression of MtIEF. Moreover, it could not be excluded that the perturbed hormonal status of the hairy roots affected the complementation results.

What can be the function of IEF and its role during IT initiation and development? Structural analysis of the IEF protein did not help us to gain insight into its function. In addition to a coiled-coil motif, only the DUF761 (pfam05553) domain of unknown function has been identified, which is unique to plants and, thus, implies a potential plant-specific biological role. DUF761-containing proteins are diverse in both length and sequence and share high-level conservation only at the DUF761 domain (Hansen et al. 2012), and no biological role has been assigned to any of them yet. Domain databases indicate DUF761 as cotton fiber-expressed proteins (Liu et al. 2008). A recent article (Zhang et al. 2019) identified 29 DUF761 domain-containing proteins in Arabidopsis and tried to determine the function of a member called DUF761-1 (encoded by At4g16790) through the analysis of mutant and overexpression lines. The multiple alignment showed that all proteins carried the DUF761 domain at their C-terminal region but otherwise were very dissimilar both in length (from 73 to 743 amino acids) and sequence. Gene expression profiling revealed that both the loss-of-function and overexpression of DUF761-1 affected the expression of many stress-, defense-, and cell-wall-related genes. In line with these observations, the overexpression of DUF761-1 resulted in distinct abnormalities in Arabidopsis vegetative and reproductive development as well as in enhanced resistance to Pseudomonas syringae pv. tomato DC3000. Unfortunately, these studies could not reveal the function of the DUF761-1 protein and the role of the DUF761 domain; thus, they could not give any clue for the function of IEF.

Homologous counterparts of MtIEF with high similarity level were only identified in leguminous plants. In these plants, however, another gene copy was also found that was named $I E F$ LIKE (IEFL). The M. truncatula IEFL protein encoded by the Medtr7g109300 gene contains the DUF761 domain as well but no predicted coiled-coil region could be identified, and it shows only a $38 \%$ identity at the amino acid level to MtIEF. Homologs of the MtIEFL gene were identified in nonleguminous plants as well, indicating that they are more common in plants. Interestingly, both genes of $M$. truncatula are expressed in the flower but only the expression of $I E F$ is associated with rhizobial infection. Because other genes have also been recruited by gene duplication for symbiosis and gained nodule-specific expression-such as, for example, the 22-kD subunit (SPC22) of the signal peptidase complex (SPC) defective in the $d n f 1$ mutants
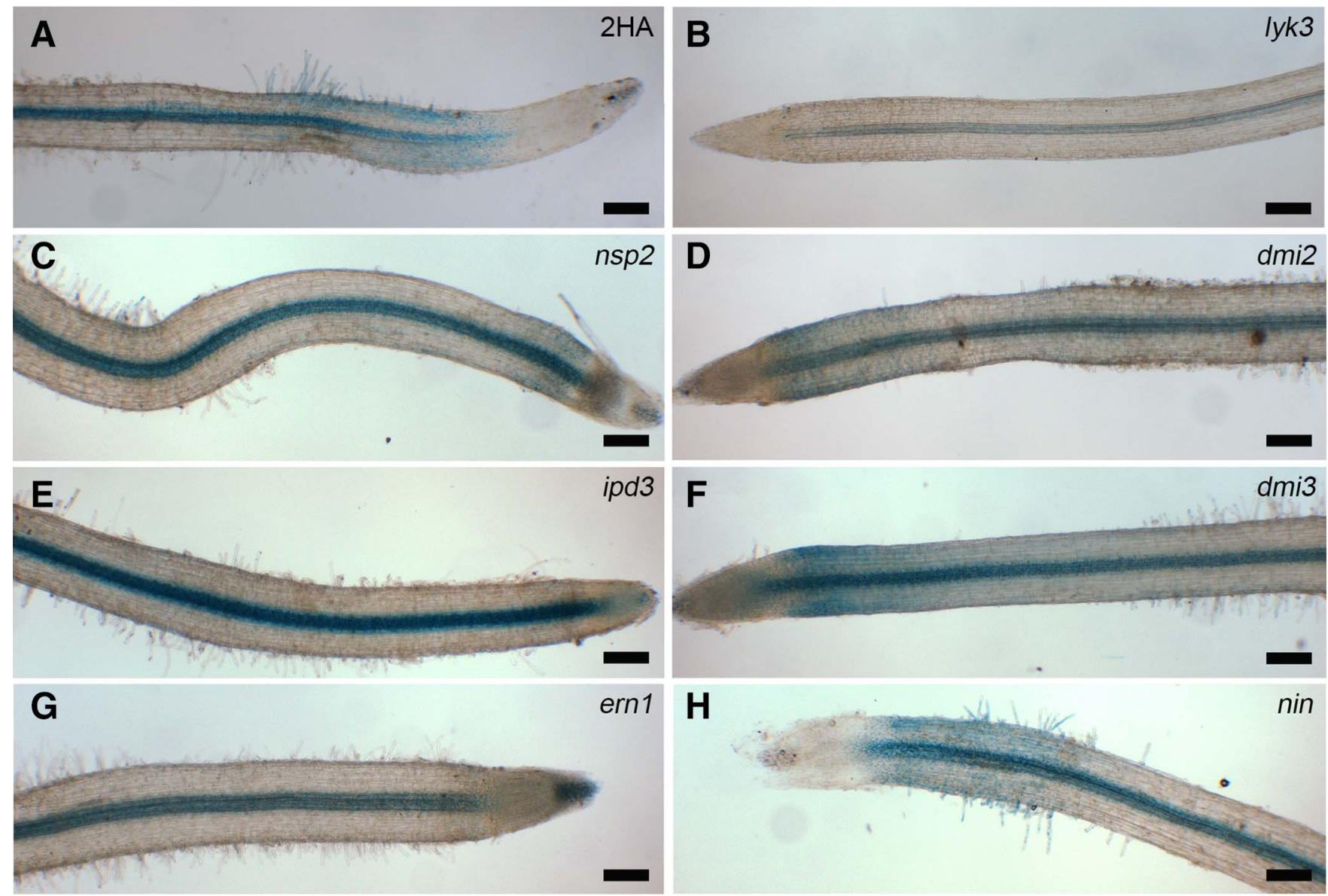

Fig. 6. Expression of MtIEF requires the activity of the Nod Factor signaling pathway. Transgenic roots with the pMtIEF::GUS transgene stained for $\beta$-glucuronidase (GUS) activity after $24 \mathrm{~h}$ of Nod factor treatment in A, wild-type $2 \mathrm{HA}$ and symbiotic mutants B, lyk3; C, nsp2; D, dmi2; E, ipd3; F, dmi3; $\mathbf{G}$, ern1; and $\mathbf{H}$, nin. Scale bars $=200 \mu \mathrm{m}$. 
(Wang et al. 2010) - it is likely that, after the duplication of the flower-specific gene, IEF has been adopted for symbiosis; more specifically, for the infection through ITs. Although the function of IEFL is also not known, an attractive hypothesis is that IEFL might be involved in polar growth of pollen tubes and the second copy, the $I E F$ gene, gained new gene regulatory elements that allowed its expression in the root and a new function for the initiation and polar growth of ITs.

Based on the symbiotic phenotype of the mutant of ief- 1 and the presence of the coiled-coil motif in the protein, we presumed that MtIEF might interact with other members of the Nod factorinduced symbiotic proteins involved in the early symbiotic events. Our data revealed that MtIEF interacts with MtRPG, another early symbiotic protein indispensable for the normal development of ITs (Arrighi et al. 2008). The MtRPG protein carries a coiled-coil region but does not contain any predicted domain with known function and, thus far, neither function nor interacting partners of MtRPG have been predicted and identified. Subcellular localization has shown that MtRPG is primarily targeted to the nucleus and, to a much lesser extent, to the cytoplasm of $N$. benthamiana cells (Arrighi et al. 2008). The distribution of MtIEF seems to be the opposite of MtRPG by being predominantly detected in the cytoplasm and less in the nucleus, which is consistent with the presence of a putative NES motif predicted at its C-terminal end. When the interaction of MtIEF and MtRPG was confirmed in the BiFC experiments, the detected signal of the interaction was more pronounced in the cytoplasm, thus resembling the localization of MtIEF when tested alone. A plausible explanation could be that the function of MtIEF is to withhold in or transport the MtRPG protein to the cytoplasm, or to mediate its active translocation from the nucleus into the cytoplasm. Because the expression of RPG is dependent on NIN (Liu et al. 2019a; Soyano et al. 2014) and independent of ERN1 (Cerri et al. 2016; Liu et al. 2019a), the interaction between IEF and RPG represents a link between the two independent transcriptional pathways regulated by NIN and ERN1 transcription factors.

ITs, similarly to root hairs and pollen tubes, extend by rapid elongation that occurs exclusively at the tip, accompanied by targeted transport of membrane vesicles, their fusion with defined sites of the cytoplasmic membrane, and delivery of their cargo to the extracellular space as well as massive cytoskeleton rearrangements. The commonality of these polar growing structures is supported by their need for certain common functions such as provided by SCAR/WAVE proteins regulating actin polymerization (Miyahara et al. 2010). Similarly, the $I E F$ and the paralogous $I E F-L I K E$ genes are expressed in floral tissues and might participate in processes involving polar growth. Throughout IT elongation, the nucleus of the root hair is in close proximity of and connected to the growing tip of the IT via an endoplasmic reticulum-rich cytoplasmic bridge. It was shown recently (Liu et al. 2019b) that MtVPY, MtLIN, and a member of the exocyst complex (MtEXO70H4), involved in the tethering and spatial targeting of membrane vesicles to the plasma membrane, localize to punctate subcellular foci where the IT will be initiated and, then, these
A

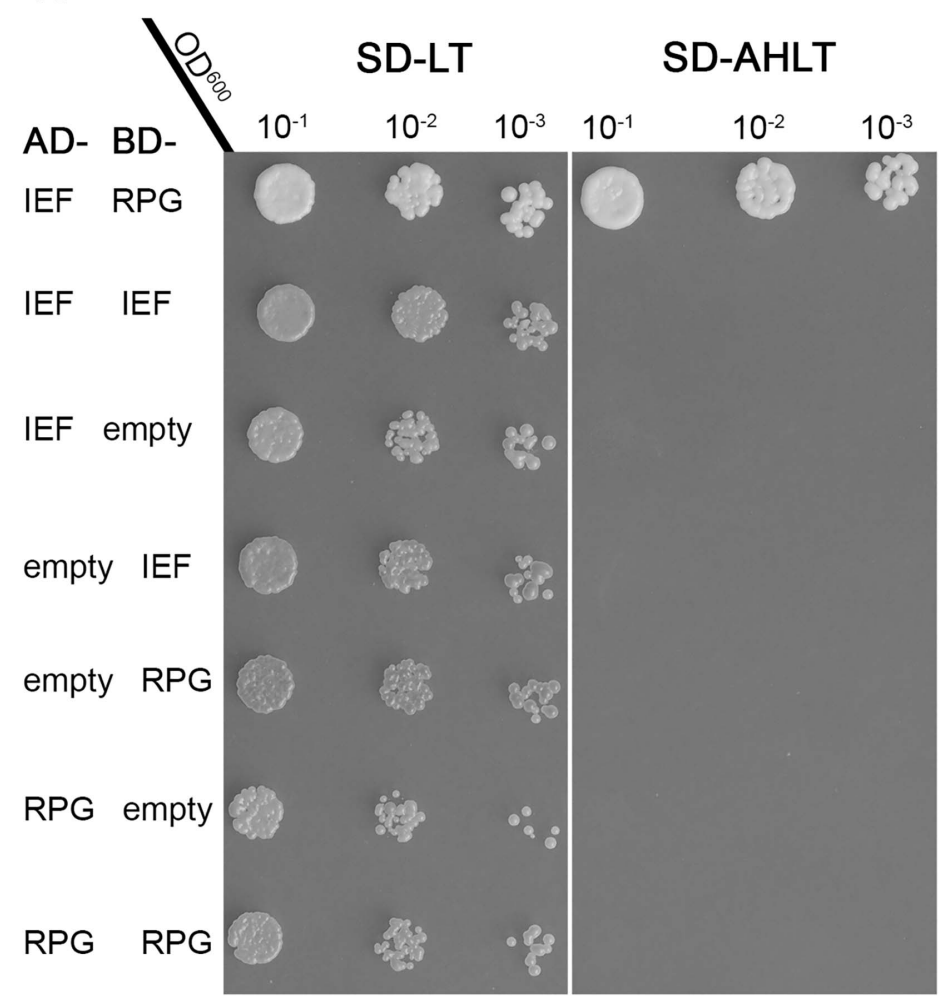

B

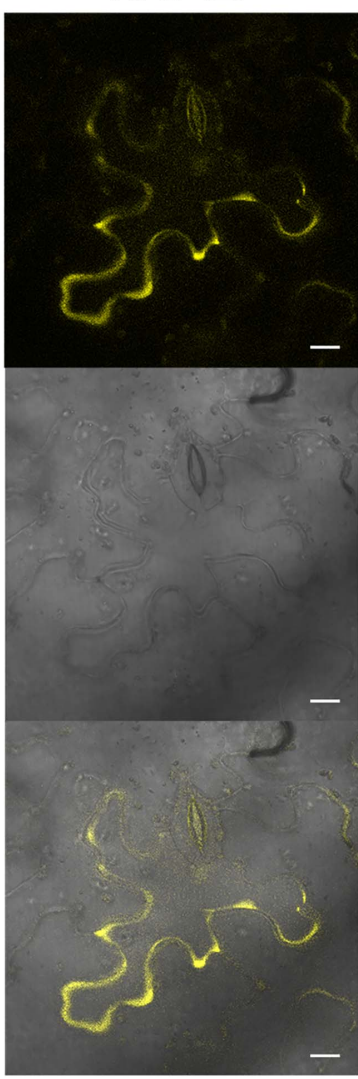

NSP1+NSP2

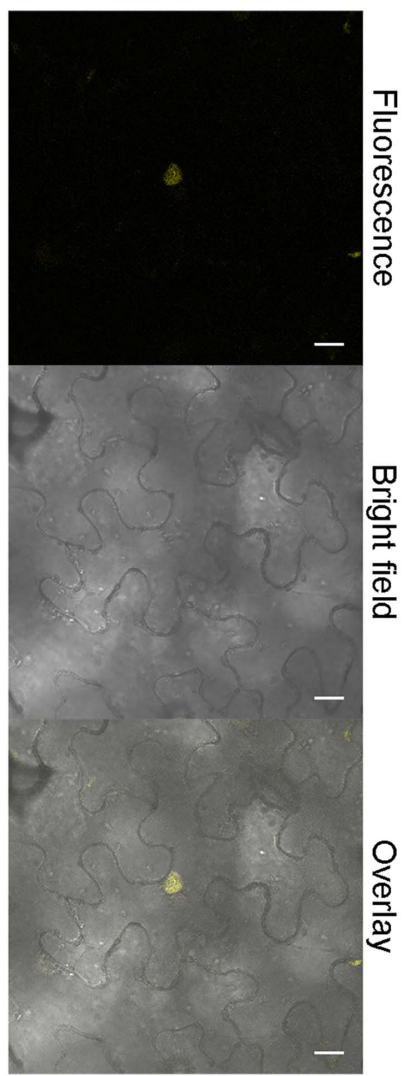

Fig. 7. Interaction between MtIEF and MtRPG shown in two experimental systems. A, Yeast-two-hybrid: MtIEF and MtRPG proteins were fused with the yeast Gal4-activation (AD) or the Gal4-binding (BD) domains and cotransformed into the Sinorhizobium cerevisiae strain PJ69-4A. Interactions were tested by comparing growth of the double transformants in the presence (SD-LT, nonselective condition) and absence (SD-AHLT, selective condition) of histidine and adenine in the medium. B, Bimolecular fluorescence complementation: N- and C-terminal parts of the yellow fluorescent protein were fused to the C-terminal part of the required for polar growth (RPG) and infection-related epidermal factor (IEF), respectively, and cotransformed into Nicotiana benthamiana leaves. The already known interaction between NSP1 and NSP2 was used as a positive control. Interactions of the proteins in leaf epidermal cells were observed with confocal microscopy 3 days after transformation. Scale bars $=10 \mu \mathrm{m}$. 
proteins are associated with both ends of the cytoplasmic bridge, at the very tip of the growing IT, and also found in the vicinity of the nucleus. Thus, the complex is believed to participate in the targeted exocytosis leading to tip growth and the polarization of the cytoplasm. It is tempting to speculate that IEF and its interacting partner, RPG, are part of the VPY-LIN complex. However, RPG might be there throughout IT initiation and growth also in the subepidermal cells whereas IEF, with its restricted expression domain, might be present only close to the cell membrane at the infection chamber and at the growing invagination. There, it might mark the site of IT initiation and the IT tip and, thus, one pole of the cytoplasm in the root hair and target elements of the VPY-LIN complex to this site. In addition, based on the complementation phenotype (less infected cells than in the WT nodules), it is possible that it also appoints the site of IT branching. To support this hypothesis, the interaction network of all proteins implicated in IT polar growth, the localization of IEF and RPG, as well as their colocalization with the VPY-LIN complex in the root hair upon rhizobial infection and the formation of the VPYLIN complex in the ief and rpg mutants need to be established.

In conclusion, our findings revealed a novel element of IT initiation and development, which is unique in that sense that-in contrast to other proteins essential for IT growth-its main act might be in the initially infected root hair. Whether it is also essential for the progression or branching or ramifying of ITs remains to be elucidated.

\section{MATERIALS AND METHODS}

Plant material, bacterial strains, and growth conditions.

$M$. truncatula mutant line F9451 was identified by screening the approximately 2,000 lines of the Tnt1/MERE1 insertion mutant collection, which was established in the Jemalong 2HA background in the frame of the European FP6 GLIP program (FOOD-CT-2004-506223 GRAIN LEGUMES IP). The 2HA genotype was used as the WT control in phenotypic characterization and cosegregation experiments. M. truncatula dmi2-1, lyk3-1, nsp2-2, ipd3-1, nin-1, dmi3-1, and ern1-1 (bit-1) mutants listed in Supplementary Table S3 were used in promoter analysis experiments. These mutants are derived from the Jemalong A17 line, which is similar to $2 \mathrm{HA}$ in the studied symbiotic phenotypes. Seeds were sterilized and germinated as described in the M. truncatula handbook (Garcia et al. 2006). Germinated seedlings were grown in zeolite substrate (Geoproduct Kft., Mád, Hungary), and watered once a week with nitrogen-free Fahraeus medium (Barker et al. 2006) supplemented with $0.5 \mathrm{mM} \mathrm{NH} \mathrm{NO}_{3}$ in a greenhouse with cycles of 16 and $8 \mathrm{~h}$ of day and night, respectively, at $25^{\circ} \mathrm{C}$. Seven-day-old seedlings were inoculated with suspension of S. medicae WSM419 at an optical density to $600 \mathrm{~nm}\left(\mathrm{OD}_{600}\right)=0.1$ carrying either the pXLGD4 plasmid (Leong et al. 1985), expressing the lacZ reporter gene under the control of the hemA promoter, or the pMEpTrpGFPGUS plasmid, expressing the GUS-GFP fusion protein under the control of the $\mathrm{pTrp}$ promoter (Auriac and Timmers 2007). In hairy root transformation and $N$. benthamiana infiltration experiments, the $A$. rhizogenes ARqual and $A$. tumefaciens $\mathrm{C} 58 \mathrm{C} 1$ strains, respectively, carrying the appropriate vector constructs were used. All bacterial strains were grown in complete yeast-tryptone agar (TA) medium supplemented with the appropriate antibiotics for 48 to $72 \mathrm{~h}$ at $30^{\circ} \mathrm{C}$.

\section{Sequencing Tht1 and MERE1 transposon flanking sites.}

Genomic DNA was isolated with QUICKGENE DNA tissue kit DT-S (Kurabo, Japan) according to the manufacturer's suggestions; only the lysis buffer was changed to cetyltrimethylammonium bromide (CTAB) buffer $(2 \%$ [wt/vol] CTAB, $0.1 \mathrm{M}$ Tris- $\mathrm{HCl}, 20 \mathrm{mM}$ EDTA, and $1.4 \mathrm{M} \mathrm{NaCl}, \mathrm{pH}=8$ ). Two- dimensional pools of $576(24 \times 24)$ genomic DNA samples from Tnt1 insertion lines were created. Approximately $2 \mu \mathrm{g}$ of DNA from each pool was sheared in a $200-\mu \mathrm{l}$ volume to obtain fragments of approximately 2,000 bp (peak) using a Covaris S2 focused-ultrasonicator with the following settings: intensity 0.1 ; duty cycle 20\%; cycles per burst 1,000; treatment time $900 \mathrm{~s}$. The fragmented DNA samples were end polished, adenylated, and phosphorylated as described by Neiman et al. (2012). A-tailed DNA fragments were ligated to an $X c m$ I-digested pBlueScript vector modified to contain a single $X \mathrm{~cm} I$ site. The ligations were used as templates in PCR assays using the vector-specific M13 (-46) sequencing primer from Thermo Fisher Scientific and biotinylaed retrotransposon specific primers Tnt1bio and MEREbio (Supplementary Table S4) targeting the nonrepeated part of the insertion elements. Fragments of 1 to $2.5 \mathrm{~kb}$ were isolated, then captured with the help of the Dynabeads kilobaseBinder kit (Thermo Fisher Scientific). In the second round of nested PCR, the IonTorrent (Thermo Fisher Scientific) specific P1 and A adaptors as well as barcodes were added and the flanking sequences were amplified with the help of the vector-specific T7_P1 and the retrotransposon-specific Tnt1A_BC1-24 and MERE1A_BC1-24 primers (Supplementary Table S4) targeting the long-terminal repeats. After quantification of the libraries, 24 samples were sequenced on the Ion318 chip with 400-bp read length.

\section{Bioinformatic analysis.}

After removing the retrotransposon sequences during the course of FST determination, reads were aligned to the $M$. truncatula genome sequence (version Mt4.0) and bins of the flanking sequences were created, then assigned to the different pools.

Search for conserved protein domains, coiled-coil motifs, secretory signal sequences, nuclear export signal sequences, and transmembrane domains were performed with the help of public online tools.

For the phylogenetic analysis, the protein sequences were identified by BLAST searches and obtained from NCBI as follows: MtIEF (AES61706), MtIEF-LIKE (XP_003625949), LjIEF (BM1847b), LjIEF-LIKE (AFK45440.1), CcIEF (XP_020210613), CcIEF-LIKE (XP_020234809), CaIEF (XP_004495922), CaIEFLIKE (XP_004494410), GmIEF A (XP_003519753), GmIEF B (XP_003536874), GmIEF-LIKE A (KRG96502), GmIEF-LIKE B (XP_006577726), GhIEF-LIKE A (XP_016747736), GhIEF-LIKE B (XP_016747630), LaIEF-LIKE A (XP_019440682), LaIEFLIKE B (XP_019414762), PvIEF (XP_007145169), PvIEFLIKE (XP_007163162), VaIEF-LIKE (XP_017416808), VaIEF (XP_017413010), TpIEF (GAU31655), TpIEF-LIKE (PNX99190), OzIEF-LIKE (XP_015643816), PsIEF-LIKE (XP_026435679), PtIEF-LIKE (XP_002302747), and VvIEF-LIKE (XP_010652228). The protein sequences were aligned using ClustalW in MEGA-X. The phylogenetic tree was constructed using the MEGA-X software (Kumar et al. 2018) by applying the neighbor-joining method using a Poisson substitution model and the bootstrap value set at 2,000.

\section{Cosegregation analysis.}

A BC1F2 population originated from line F9451V and segregating the symbiotic phenotype was generated. First, the mutant individual was back-crossed using the WT 2HA plants as pollinator; thus, the hybrid nature of the $\mathrm{BC} 1$ offspring was detectable by their WT symbiotic phenotype. Then, the BC1F2 population segregating the ief-1 mutation was created by self-pollinating the BC1 plants. In total, 37 individuals were grown from this population and inoculated with $S$. medicae WSM419 (pXLGD4), and the symbiotic phenotype was assessed at $21 \mathrm{dpi}$. In order to get genotype data on the candidate genes, genomic DNA from the same set of individuals was isolated using the QuickGene DNA isolation kit (Autogen Inc.). Genotyping was done by detecting the WT and the mutant alleles of the candidate genes using PCR 
assays with specifically designed gene-specific and insertionspecific primers, as listed in Supplementary Table S2.

\section{Histochemical stainings and light microscopic analysis.}

Root and nodule samples were carefully harvested at different time points upon inoculation with rhizobia. For GUS staining, plant tissues were embedded in $5 \%$ agarose, and $70-\mu \mathrm{m}$ cross sections or longitudinal sections were prepared from nodules and $60-\mu \mathrm{m}$ cross sections from roots using a MICROM HM $650 \mathrm{~V}$ vibratome.

For GUS activity staining, nodule sections or whole roots were vacuum-infiltrated for $30 \mathrm{~min}$ and then incubated in GUS staining solution (2 mM 5-bromo-4-chloro-3-indolyl $\beta$-D-glucuronide [Duchefa Biochemie], $1 \mathrm{mM}$ EDTA, $0.1 \%$ Triton X-100, $0.1 \%$ sarcosyl, $0.05 \%$ sodium dodecyl sulfate, $1 \mathrm{mM}$ potassium ferricyanide, and $1 \mathrm{mM}$ ferrocyanide in phosphate-buffered saline [PBS] [pH 7.4]) at $37^{\circ} \mathrm{C}$ for a time period of 1 to $6 \mathrm{~h}$. For the detection of LacZ activity, nodule sections were vacuum infiltrated for $30 \mathrm{~min}$ and postfixed for $60 \mathrm{~min}$ in $1.5 \%$ glutaraldehyde (Sigma) solution in PBS ( $\mathrm{pH} 7.4$ ), followed by rinsing in PBS (pH 7.4) three times, then incubated in $0.1 \mathrm{M}$ 5-bromo-4chloro-3-indolyl $\beta$-D-galactopyranoside in PBS (pH 7.4) supplemented with $5 \mathrm{mM}$ potassium ferricyanide and $5 \mathrm{mM}$ potassium ferrocyanide at $37^{\circ} \mathrm{C}$ for $1 \mathrm{~h}$. For GUS-LacZ double staining, transgenic roots were first incubated in $2 \mathrm{mM}$ 5-bromo-6-chloro3-indolyl- $\beta$-D-glucuronic acid, cyclohexyl ammonium salt (Duchefa Biochemie) in PBS (pH 7.4), supplemented with $5 \mathrm{mM}$ potassium ferricyanide and $5 \mathrm{mM}$ potassium ferrocyanide at $37^{\circ} \mathrm{C}$ for 4 to $6 \mathrm{~h}$ (using vacuum infiltration in the first $30 \mathrm{~min}$ ) for GUS staining. Samples were then fixed in $1.5 \%$ glutaraldehyde, followed by washing steps and staining for $\beta$-galactosidase activity as described above.

The stained sections and whole roots were observed using the Leica DM LB2 light microscope with $\times 10, \times 20$, and $\times 40$ objectives and the images were captured using the QImaging MicroPublisher 3.3 RTV camera.

\section{Generating constructs.}

Most constructs were generated using Gateway Technology (Life Technologies). PCR fragments harboring the $M$. truncatula IEF gene were amplified from the mth2-4o4 BAC clone, while full-length cDNA of $L I N$ and $R P G$ were amplified using an $M$. truncatula A17 cDNA template, made from RNA purified from symbiotic tissues with a NucleoSpin RNA Plant Kit (MachereyNagel), and reverse transcribed using the Applied Biosystems High-Capacity cDNA Reverse Transcription Kit. DNA fragments were amplified using the Phusion DNA polymerase (Thermo Fisher Scientific) and the primers listed in Supplementary Table S2, followed by adding an extra A nucleotide to the $3^{\prime}$ end by incubation with DreamTaq polymerase (Thermo Scientific). A-tailed PCR fragments were then cloned into the pCR8/ GW/TOPO vector (Invitrogen). The entry clones containing the $I P D 3$ and DMI3 coding sequences in pDONR207 were kindly provided by Peter Kaló (Horváth et al. 2011), while the NSPI and NSP2 expression clones were kindly provided by Giles E. D. Oldroyd (Hirsch et al. 2009). The DNA fragments in entry clones were inserted into destination vectors via LR clonase II reaction (Invitrogen): The 1.9-kbp MtIEF promoter fragment was inserted into pMDC164-RR vector for promoter-GUS assays (Curtis and Grossniklaus 2003). Three destination vectors were created for the complementation experiments: The 2,665-bp genomic fragment containing the $1.9-\mathrm{kbp}$ promoter fragment and the coding region of $I E F$ was cloned into pKGW-RR (Karimi et al. 2002); the MtIEF coding region was inserted into pK7WG2D-RR (Karimi et al. 2002) and pUB-GW-GFP (Maekawa et al. 2008) behind the cauliflower mosaic virus $35 \mathrm{~S}$ and $L$. japonicus ubiquitin promoters, respectively, for constitutive expression. To generate
$\mathrm{N}$ - or C-terminal split-YFP fusions for BiFC experiments, the $I E F$ and $R P G$ sequences were recombined into destination vectors pUBC-nYFP-DEST and pUBC-cYFP-DEST (Grefen et al. 2010). The full-length NSP1 and NSP2 genes for the BiFC experiments were available in the pUBN-nYFP-DEST and pUBN-cYFP-DEST, respectively (Hirsch et al. 2009). For yeast two-hybrid experiments, DNA fragments from the entry clones were recombined into pDEST-GBKT7 and pDEST-GADT7 vectors (Clontech Laboratories, Inc.). The PCR fragments of the intracellular part of DMI2 (NORK), NFP, and LYK3 (amplified as described above) were ligated into the linearized vectors of pGADT7 and pGBKT7 digested with EcoRI and BamHI restriction enzymes.

\section{Isolation or purification of rhizobial exudates containing Nod factors.}

For the purification of rhizobial exudates containing the symbiotic signal molecules, a modified protocol published by Baev et al. (1991) was used. $S$. medicae strain WSM419 cells were grown with shaking at $240 \mathrm{rpm}$ at $30^{\circ} \mathrm{C}$ in TA medium containing chloramphenicol (Duchefa) at $20 \mu \mathrm{g} / \mathrm{ml}$ until log phase $\left(\mathrm{OD}_{600}=0.5\right.$ to 0.6$)$. The bacterial culture was then cooled on ice and cells were collected by centrifugation at $2,000 \times g$ for $25 \mathrm{~min}$. The pellet of bacteria was washed twice with Fahraeus medium. Then, bacteria were suspended in the same volume of Fahraeus medium containing $10 \mu \mathrm{M}$ luteolin (Sigma) and incubated with shaking at $30^{\circ} \mathrm{C}$ for $16 \mathrm{~h}$. Culture was chilled on ice and centrifuged at $2,000 \times g$ for $25 \mathrm{~min}$. To remove residual bacterial cells, the supernatant was filtered through a $45-\mu \mathrm{m}$ pore size unit. Transgenic roots were incubated with this supernatant diluted 10x with Fahraeus medium. Control (i.e., no Nod factor) treatments were performed with Fahraeus plant medium.

\section{Yeast two-hybrid experiments.}

Bait and prey plasmids were transformed into Saccharomyces cerevisiae PJ-69-4A cells as recommended by the manufacturer (protocol number PT3247-1.2; Clontech Laboratories, Inc.) using the original components and salmon testes DNA (Sigma) as carrier. Transformed PJ-69-4A yeast strains were selected on SD (dropout)/-Leu and Trp (-LW) plates. Expression of the HIS3 and $A D E 2$ reporter genes was assayed using spot assay. PJ-69$4 \mathrm{~A}$ yeast strains containing the appropriate constructs were grown in SD-LW medium with shaking at $30^{\circ} \mathrm{C}$ for $16 \mathrm{~h}$. The 10x-diluted cultures were spotted onto SD-LW, SD-HLW, and SD-AHLW plates to monitor growth.

\section{Plant transformation.}

The constructs generated for plant transformation experiments were introduced into A. tumefaciens strain $\mathrm{C} 58 \mathrm{C} 1$ or A. rhizogenes strain ARqual by electroporation.

To perform hairy root transformation, a slightly modified protocol derived from Kiss et al. (2009) was used. Briefly, the root tips of the seedlings were cut with a blade and dipped into the culture of A. rhizogenes strain Arqual carrying the construct of interest. The seedlings were kept in square Petri dishes on wet and sterile filter paper only for $2 \mathrm{~h}$; then, they were put into zeolite substrate and kept in rhizobia-free condition for 14 to 21 days to allow hairy roots to grow. The plants were watered daily with sterile distilled water and with Fahraeus medium once a week. For spontaneous nodulation tests, the plants were kept in rhizobia-free conditions for another 4 weeks. For promoter analysis and complementation assays, the transgenic roots were inoculated with Sinorhizobium medicae strain WSM419, as described above.

For the infiltration of $N$. benthamiana leaves, a single $A$. tumefaciens colony was inoculated into $5 \mathrm{ml}$ of Luria-Bertani (LB) medium and grown at $28^{\circ} \mathrm{C}$ with shaking for $16 \mathrm{~h}$. Then, $1 \mathrm{ml}$ of 
bacterial culture was transferred into $20 \mathrm{ml}$ of fresh LB medium containing $10 \mathrm{mM}$ morpholineethanesulfonic acid (MES) (pH 5.6), $20 \mu \mathrm{M}$ acetosyringone (Sigma), and appropriate antibiotics. After growth for $16 \mathrm{~h}$ at $28^{\circ} \mathrm{C}$, the bacterial cultures were centrifuged at 4,000 rpm for $15 \mathrm{~min}$. The pellet was suspended in sterile water containing $10 \mathrm{mM}$ MES ( $\mathrm{pH} 5.6$ ), $10 \mathrm{mM}$ $\mathrm{MgCl}_{2}$, and $150 \mu \mathrm{M}$ acetosyringone (MMA solution). The Agrobacterium strain carrying the target construct grown to $\mathrm{OD}_{600}=$ 0.3 (localization experiment) or equal volumes of Agrobacterium strains carrying the paired vector combinations (BiFC experiments) were mixed with the strain carrying the p19 silencing suppressor construct (Silhavy et al. 2002) and infiltrated into the top leaves of 6-week-old $N$. benthamiana plants. Prior to infiltration, the solution of the strains was kept at room temperature for at least $3 \mathrm{~h}$ without shaking in darkness. Infiltration of the fully expanded leaves was performed with a 1-ml disposable syringe and the plants were kept in darkness overnight to enhance the transformation efficiency. YFP fluorescence was observed 3 to 4 days after infiltration using a Leica confocal microscope with the YFP preset of excitation at $514 \mathrm{~nm}$ and fluorescence detection between 525 and $600 \mathrm{~nm}$.

\section{ACKNOWLEDGMENTS}

We thank É. Kondorosi for the financial support of her Balzan research project, É. Kondorosi and P. Kaló for critical reading of the manuscript, and P. Ratet and the community of the European FP6 GLIP program (FOOD-CT-2004-506223 GRAIN LEGUMES IP) for the generation of the Tnt1 insertion lines in the M. truncatula Jemalong 2HA genotype.

\section{AUTHOR-RECOMMENDED INTERNET RESOURCES}

Search for conserved protein domains:

https://www.ncbi.nlm.nih.gov/Structure/cdd/wrpsb.cgi

Search for secretory signal sequences: http://www.cbs.dtu.dk/services/SignalP/

Search for nuclear export signal sequences:

http://www.cbs.dtu.dk/services/NetNES/

Search for transmembrane domains: http://www.cbs.dtu.dk/services/TMHMM/ ClustalW: https://www.ebi.ac.uk/Tools/msa/clustalw2/

MEGA-X: https://www.megasoftware.net

\section{LITERATURE CITED}

Arrighi, J. F., Godfroy, O., de Billy, F., Saurat, O., Jauneau, A., and Gough, C. 2008. The RPG gene of Medicago truncatula controls Rhizobium-directed polar growth during infection. Proc. Natl. Acad. Sci. U.S.A. 105:9817-9822.

Auriac, M. C., and Timmers, A. C. 2007. Nodulation studies in the model legume Medicago truncatula: Advantages of using the constitutive EF $1 \propto \alpha$ promoter and limitations in detecting fluorescent reporter proteins in nodule tissues. Mol. Plant-Microbe Interact. 20:1040-1047.

Baev, N., Endre, G., Petrovics, G., Banfalvi, Z., and Kondorosi, A. 1991. Six nodulation genes of nod box locus 4 in Rhizobium meliloti are involved in nodulation signal production: nodM codes for D-glucosamine synthetase. Mol. Gen. Genet. 228:113-124.

Barker, D. G., Pfaff, T., Moreau, D., Groves, E., Ruffel, S., Lepetit, M., Whitehand, S., Maillet, F., Nair, R. M., and Journet, E.-P. 2006. Growing M. truncatula: Choice of substrates and growth conditions. In: Medicago truncatula handbook. Nobel Research Institute. https:// www.noble.org/medicago-handbook/

Benedito, V. A., Torres-Jerez, I., Murray, J. D., Andriankaja, A., Allen, S., Kakar, K., Wandrey, M., Verdier, J., Zuber, H., Ott, T., Moreau, S., Niebel, A., Frickey, T., Weiller, G., He, J., Dai, X., Zhao, P. X., Tang, Y., and Udvardi, M. K. 2008. A gene expression atlas of the model legume Medicago truncatula. Plant J. 55:504-513.

Breakspear, A., Liu, C., Roy, S., Stacey, N., Rogers, C., Trick, M., Morieri, G., Mysore, K. S., Wen, J., Oldroyd, G. E. D., Downie, J. A., and Murray, J. D. 2014. The root hair "infectome" of Medicago truncatula uncovers changes in cell cycle genes and reveals a requirement for Auxin signaling in rhizobial infection. Plant Cell 26:4680-4701.

Catoira, R., Galera, C., de Billy, F., Penmetsa, R. V., Journet, E. P., Maillet, F., Rosenberg, C., Cook, D., Gough, C., and Dénarié, J. 2000.
Four genes of Medicago truncatula controlling components of a Nod factor transduction pathway. Plant Cell 12:1647-1665.

Cerri, M. R., Frances, L., Kelner, A., Fournier, J., Middleton, P. H., Auriac, M. C., Mysore, K. S., Wen, J., Erard, M., Barker, D. G., Oldroyd, G. E., and de Carvalho-Niebel, F. 2016. The symbiosis-related ERN transcription factors act in concert to coordinate rhizobial host root infection. Plant Physiol. 171:1037-1054.

Curtis, M. D., and Grossniklaus, U. 2003. A gateway cloning vector set for high-throughput functional analysis of genes in planta. Plant Physiol. 133:462-469.

Damiani, I., Drain, A., Guichard, M., Balzergue, S., Boscari, A., Boyer, J. C., Brunaud, V., Cottaz, S., Rancurel, C., Da Rocha, M., Fizames, C., Fort, S., Gaillard, I., Maillol, V., Danchin, E. G. J., Rouached, H., Samain, E., Su, Y. H., Thouin, J., Touraine, B., Puppo, A., Frachisse, J. M., Pauly, N., and Sentenac, H. 2016. Nod factor effects on root hair-specific transcriptome of Medicago truncatula: Focus on plasma membrane transport systems and reactive oxygen species networks. Front. Plant Sci. 7:794.

Fliegmann, J., and Bono, J. J. 2015. Lipo-chitooligosaccharidic nodulation factors and their perception by plant receptors. Glycoconj. J. 32: 455-464.

Fournier, J., Teillet, A., Chabaud, M., Ivanov, S., Genre, A., Limpens, E., de Carvalho-Niebel, F., and Barker, D. G. 2015. Remodeling of the infection chamber before infection thread formation reveals a two-step mechanism for rhizobial entry into the host legume root hair. Plant Physiol. 167:1233-1242.

Fournier, J., Timmers, A. C. J., Sieberer, B. J., Jauneau, A., Chabaud, M., and Barker, D. G. 2008. Mechanism of infection thread elongation in root hairs of Medicago truncatula and dynamic interplay with associated rhizobial colonization. Plant Physiol. 148:1985-1995.

Gage, D. J. 2004. Infection and invasion of roots by symbiotic, nitrogenfixing rhizobia during nodulation of temperate legumes. Microbiol Mol. Biol. Rev. 68:280-300.

Garcia, J., Barker, D. G., and Journet, E. P. 2006. Seed storage and germination. In: Medicago truncatula handbook. Nobel Research Institute. https://www.noble.org/medicago-handbook/

Gavrin, A., Rey, T., Torode, T. A., Toulotte, J., Chatterjee, A., Kaplan, J. L., Evangelisti, E., Takagi, H., Charoensawan, V., Rengel, D., Journet, E. P., Debellé, F., de Carvalho-Niebel, F., Terauchi, R., Braybrook, S., and Schornack, S. 2020. Developmental Modulation of Root Cell Wall Architecture Confers Resistance to an Oomycete Pathogen. Curr. Biol. 30:4165-4176.e5.

Gibson, K. E., Kobayashi, H., and Walker, G. C. 2008. Molecular determinants of a symbiotic chronic infection. Annu. Rev. Genet. 42:413441.

Gleason, C., Chaudhuri, S., Yang, T., Muñoz, A., Poovaiah, B. W., and Oldroyd, G. E. D. 2006. Nodulation independent of rhizobia induced by a calcium-activated kinase lacking autoinhibition. Nature 441:1149-1152.

Grefen, C., Donald, N., Hashimoto, K., Kudla, J., Schumacher, K., and Blatt, M. R. 2010. A ubiquitin-10 promoter-based vector set for fluorescent protein tagging facilitates temporal stability and native protein distribution in transient and stable expression studies. Plant J. 64:355365.

Hansen, S. F., Harholt, J., Oikawa, A., and Scheller, H. V. 2012. Plant glycosyltransferases beyond CAZy: A perspective on DUF families. Front. Plant Sci. 3:59.

He, J., Benedito, V. A., Wang, M., Murray, J. D., Zhao, P. X., Tang, Y., and Udvardi, M. K. 2009. The Medicago truncatula gene expression atlas web server. BMC Bioinf. 10:441.

Hirsch, S., Kim, J., Muñoz, A., Heckmann, A. B., Downie, J. A., and Oldroyd, G. E. D. 2009. GRAS proteins form a DNA binding complex to induce gene expression during nodulation signaling in Medicago truncatula. Plant Cell 21:545-557.

Horváth, B., Yeun, L. H., Domonkos, A., Halász, G., Gobbato, E., Ayaydin, F., Miró, K., Hirsch, S., Sun, J., Tadege, M., Ratet, P., Mysore, K. S., Ané, J. M., Oldroyd, G. E. D., and Kaló, P. 2011. Medicago truncatula IPD3 is a member of the common symbiotic signaling pathway required for rhizobial and mycorrhizal symbioses. Mol. Plant-Microbe Interact. 24: 1345-1358.

Hossain, M. S., Liao, J., James, E. K., Sato, S., Tabata, S., Jurkiewicz, A., Madsen, L. H., Stougaard, J., Ross, L., and Szczyglowski, K. 2012. Lotus japonicus ARPC1 is required for rhizobial infection. Plant Physiol. 160:917-928.

Iantcheva, A., Chabaud, M., Cosson, V., Barascud, M., Schutz, B., PrimardBrisset, C., Durand, P., Barker, D. G., Vlahova, M., and Ratet, P. 2009 Osmotic shock improves Tnt1 transposition frequency in Medicago truncatula cv Jemalong during in vitro regeneration. Plant Cell Rep. 28:15631572 . 
Ivanov, S., Fedorova, E. E., Limpens, E., De Mita, S., Genre, A., Bonfante, P., and Bisseling, T. 2012. Rhizobium-legume symbiosis shares an exocytotic pathway required for arbuscule formation. Proc. Natl. Acad. Sci. U.S.A. 109:8316-8321.

Jin, Y., Chen, Z., Yang, J., Mysore, K. S., Wen, J., Huang, J., Yu, N., and Wang, E. 2018. IPD3 and IPD3L function redundantly in rhizobial and mycorrhizal symbioses. Front. Plant Sci. 9:267.

Jin, Y., Liu, H., Luo, D., Yu, N., Dong, W., Wang, C., Zhang, X., Dai, H., Yang, J., and Wang, E. 2016. DELLA proteins are common components of symbiotic rhizobial and mycorrhizal signalling pathways. Nat. Commun. 7:12433.

Kaló, P., Gleason, C., Edwards, A., Marsh, J., Mitra, R. M., Hirsch, S., Jakab, J., Sims, S., Long, S. R., Rogers, J., Kiss, G. B., Downie, J. A., and Oldroyd, G. E. 2005. Nodulation signaling in legumes requires NSP2, a member of the GRAS family of transcriptional regulators. Science 308:1786-1789.

Karimi, M., Inzé, D., and Depicker, A. 2002. GATEWAY vectors for Agrobacterium-mediated plant transformation. Trends Plant Sci. 7: 193-195.

Kawaharada, Y., Kelly, S., Nielsen, M. W., Hjuler, C. T., Gysel, K., Muszyński, A., Carlson, R. W., Thygesen, M. B., Sandal, N., Asmussen, M. H., Vinther, M., Andersen, S. U., Krusell, L., Thirup, S., Jensen, K. J., Ronson, C. W., Blaise, M., Radutoiu, S., and Stougaard, J. 2015. Receptor-mediated exopolysaccharide perception controls bacterial infection. Nature 523:308-312.

Kiss, E., Oláh, B., Kaló, P., Morales, M., Heckmann, A. B., Borbola, A., Lózsa, A., Kontár, K., Middleton, P., Downie, J. A., Oldroyd, G. E. D., and Endre, G. 2009. LIN, a novel type of U-box/WD40 protein, controls early infection by rhizobia in legumes. Plant Physiol. 151:1239-1249.

Kumar, S., Stecher, G., Li, M., Knyaz, C., and Tamura, K. 2018. MEGA $\mathrm{X}$ : Molecular evolutionary genetics analysis across computing platforms. Mol. Biol. Evol. 35:1547-1549.

Laloum, T., Baudin, M., Frances, L., Lepage, A., Billault-Penneteau, B., Cerri, M. R., Ariel, F., Jardinaud, M. F., Gamas, P., de Carvalho-Niebel, F., and Niebel, A. 2014. Two CCAAT-box-binding transcription factors redundantly regulate early steps of the legume-rhizobia endosymbiosis. Plant J. 79:757-768.

Laporte, P., Lepage, A., Fournier, J., Catrice, O., Moreau, S., Jardinaud, M. F., Mun, J. H., Larrainzar, E., Cook, D. R., Gamas, P., and Niebel, A. 2014. The CCAAT box-binding transcription factor NF-YA1 controls rhizobial infection. J. Exp. Bot. 65:481-494.

Leong, S. A., Williams, P. H., and Ditta, G. S. 1985. Analysis of the 5 regulatory region of the gene for delta-aminolevulinic acid synthetase of Rhizobium meliloti. Nucleic Acids Res. 13:5965-5976.

Li, X., Zheng, Z., Kong, X., Xu, J., Qiu, L., Sun, J., Reid, D., Jin, H., Andersen, S. U., Oldroyd, G. E. D., Stougaard, J., Downie, J. A., and Xie, F. 2019. Atypical receptor kinase RINRK1 required for rhizobial infection but not nodule development in Lotus japonicus. Plant Physiol. 181:804-816

Limpens, E., Mirabella, R., Fedorova, E., Franken, C., Franssen, H., Bisseling, T., and Geurts, R. 2005. Formation of organelle-like N2-fixing symbiosomes in legume root nodules is controlled by DMI2. Proc. Natl. Acad. Sci. U.S.A. 102:10375-10380.

Liu, C.-W., Breakspear, A., Guan, D., Cerri, M. R., Jackson, K., Jiang, S., Robson, F., Radhakrishnan, G. V., Roy, S., Bone, C., Stacey, N., Rogers, C., Trick, M., Niebel, A., Oldroyd, G. E. D., de Carvalho-Niebel, F., and Murray, J. D. 2019a. NIN acts as a network hub controlling a growth module required for rhizobial infection. Plant Physiol. 179:17041722.

Liu, C.-W., Breakspear, A., Stacey, N., Findlay, K., Nakashima, J., Ramakrishnan, K., Liu, M., Xie, F., Endre, G., de Carvalho-Niebel, F., Oldroyd, G. E. D., Udvardi, M. K., Fournier, J., and Murray, J. D. 2019 b. A protein complex required for polar growth of rhizobial infection threads. Nat. Commun. 10:2848.

Liu, C.-W., and Murray, J. D. 2016. The role of flavonoids in nodulation host-range specificity: An update. Plants 5:33.

Liu, D. Q., Tu, L. L., Li, Y. J., Wang, L., Zhu, L. F., and Zhang, X. L. 2008. Genes encoding fasciclin-like arabinogalactan proteins are specifically expressed during cotton fiber development. Plant Mol. Biol. Rep. 26:98-113.

Liu, J., Rutten, L., Limpens, E., van der Molen, T., van Velzen, R., Chen, R., Chen, Y., Geurts, R., Kohlen, W., Kulikova, O., and Bisseling, T. 2019. A remote cis-regulatory region is required for NIN Expression in the pericycle to initiate nodule primordium formation in Medicago truncatula. Plant Cell 31:68-83.

Maekawa, T., Kusakabe, M., Shimoda, Y., Sato, S., Tabata, S., Murooka, Y., and Hayashi, M. 2008. Polyubiquitin promoter-based binary vectors for overexpression and gene silencing in Lotus japonicus. Mol. Plant-Microbe Interact. 21:375-382.

Marsh, J. F., Rakocevic, A., Mitra, R. M., Brocard, L., Sun, J., Eschstruth, A., Long, S. R., Schultze, M., Ratet, P., and Oldroyd, G. E. D. 2007. Medicago truncatula NIN is essential for rhizobialindependent nodule organogenesis induced by autoactive calcium/calmodulin-dependent protein kinase. Plant Physiol. 144:324-335.

Mei, K., and Guo, W. 2018. The exocyst complex. Curr. Biol. 28:R922R925.

Middleton, P. H., Jakab, J., Penmetsa, R. V., Starker, C. G., Doll, J. Kaló, P., Prabhu, R., Marsh, J. F., Mitra, R. M., Kereszt, A., Dudas, B., VandenBosch, K., Long, S. R., Cook, D. R., Kiss, G. B., and Oldroyd, G. E. 2007. An ERF transcription factor in Medicago truncatula that is essential for Nod factor signal transduction. Plant Cell 19:1221 1234

Miyahara, A., Richens, J., Starker, C., Morieri, G., Smith, L., Long, S., Downie, J. A., and Oldroyd, G. E. D. 2010. Conservation in function of a SCAR/WAVE component during infection thread and root hair growth in Medicago truncatula. Mol. Plant-Microbe Interact. 23:15531562

Murray, J. D. 2011. Invasion by invitation: Rhizobial infection in legumes. Mol. Plant-Microbe Interact. 24:631-639.

Neiman, M., Sundling, S., Grönberg, H., Hall, P., Czene, K., Lindberg, J., and Klevebring, D. 2012. Library preparation and multiplex capture for massive parallel sequencing applications made efficient and easy. PLoS One 7:e48616.

Oldroyd, G. E. D., Murray, J. D., Poole, P. S., and Downie, J. A. 2011 The rules of engagement in the legume-rhizobial symbiosis. Annu. Rev. Genet. 45:119-144.

Pumplin, N., Mondo, S. J., Topp, S., Starker, C. G., Gantt, J. S., and Harrison, M. J. 2010. Medicago truncatula Vapyrin is a novel protein required for arbuscular mycorrhizal symbiosis. Plant J. 61:482-494.

Qiu, L., Lin, J. S., Xu, J., Sato, S., Parniske, M., Wang, T. L., Downie, J. A., and Xie, F. 2015. SCARN a novel class of SCAR protein that is required for root-hair infection during legume nodulation. PLoS Genet. 11:e1005623.

Rakocevic, A., Mondy, S., Tirichine, L., Cosson, V., Brocard, L., Iantcheva, A., Cayrel, A., Devier, B., Abu El-Heba, G. A., and Ratet, P. 2009. MERE1, a low-copy-number copia-type retroelement in Medicago truncatula active during tissue culture. Plant Physiol. 151:1250-1263.

Roth, L. E., and Stacey, G. 1989. Bacterium release into host cells of nitrogen-fixing soybean nodules: The symbiosome membrane comes from three sources. Eur. J. Cell Biol. 49:13-23.

Roux, B., Rodde, N., Jardinaud, M. F., Timmers, T., Sauviac, L., Cottret, L., Carrère, S., Sallet, E., Courcelle, E., Moreau, S., Debellé, F., Capela, D., de Carvalho-Niebel, F., Gouzy, J., Bruand, C., and Gamas, P. 2014. An integrated analysis of plant and bacterial gene expression in symbiotic root nodules using laser-capture microdissection coupled to RNA sequencing. Plant J. 77:817-837.

Rutten, P. J., and Poole, P. S. 2019. Oxygen regulatory mechanisms of nitrogen fixation in rhizobia. Adv. Microb. Physiol. 75:325-389.

Schauser, L., Roussis, A., Stiller, J., and Stougaard, J. 1999. A plant regulator controlling development of symbiotic root nodules. Nature 402:191-195.

Silhavy, D., Molnár, A., Lucioli, A., Szittya, G., Hornyik, C., Tavazza, M., and Burgyán, J. 2002. A viral protein suppresses RNA silencing and binds silencing-generated, 21- to 25-nucleotide double-stranded RNAs. EMBO J. 21:3070-3080.

Sinharoy, S., Liu, C., Breakspear, A., Guan, D., Shailes, S., Nakashima, J., Zhang, S., Wen, J., Torres-Jerez, I., Oldroyd, G., Murray, J. D., and Udvardi, M. K. 2016. A Medicago truncatula cystathionine- $\beta$-synthaselike domain-containing protein is required for rhizobial infection and symbiotic nitrogen fixation. Plant Physiol. 170:2204-2217.

Smit, P., Raedts, J., Portyanko, V., Debellé, F., Gough, C., Bisseling, T., and Geurts, R. 2005. NSP1 of the GRAS protein family is essential for rhizobial Nod factor-induced transcription. Science 308:1789-1791.

Soyano, T., Hirakawa, H., Sato, S., Hayashi, M., and Kawaguchi, M. 2014. Nodule inception creates a long-distance negative feedback loop involved in homeostatic regulation of nodule organ production. Proc. Natl. Acad. Sci. U.S.A. 111:14607-14612

Tadege, M., Wen, J., He, J., Tu, H., Kwak, Y., Eschstruth, A., Cayrel, A., Endre, G., Zhao, P. X., Chabaud, M., Ratet, P., and Mysore, K. S 2008. Large-scale insertional mutagenesis using the Tnt1 retrotransposon in the model legume Medicago truncatula. Plant J. 54:335-347.

Vernié, T., Kim, J., Frances, L., Ding, Y., Sun, J., Guan, D., Niebel, A., Gifford, M. L., de Carvalho-Niebel, F., and Oldroyd, G. E. 2015. The NIN transcription factor coordinates diverse nodulation programs in different tissues of the Medicago truncatula root. Plant Cell 27:34103424 
Wang, D., Griffitts, J., Starker, C., Fedorova, E., Limpens, E., Ivanov, S., Bisseling, T., and Long, S. 2010. A nodule-specific protein secretory pathway required for nitrogen-fixing symbiosis. Science 327:11261129.

Xiao, T. T., Schilderink, S., Moling, S., Deinum, E. E., Kondorosi, E., Franssen, H., Kulikova, O., Niebel, A., and Bisseling, T. 2014. Fate map of Medicago truncatula root nodules. Development 141:35173528.

Xie, F., Murray, J. D., Kim, J., Heckmann, A. B., Edwards, A., Oldroyd, G. E. D., and Downie, J. A. 2012. Legume pectate lyase required for root infection by rhizobia. Proc. Natl. Acad. Sci. U.S.A. 109:633-638.

Yano, K., Shibata, S., Chen, W. L., Sato, S., Kaneko, T., Jurkiewicz, A., Sandal, N., Banba, M., Imaizumi-Anraku, H., Kojima, T., Ohtomo, R., Szczyglowski, K., Stougaard, J., Tabata, S., Hayashi, M., Kouchi, H., and Umehara, Y. 2009. CERBERUS, a novel U-box protein containing WD-40 repeats, is required for formation of the infection thread and nodule development in the legume-Rhizobium symbiosis. Plant J. 60: 168-180.

Yokota, K., Fukai, E., Madsen, L. H., Jurkiewicz, A., Rueda, P., Radutoiu, S., Held, M., Hossain, M. S., Szczyglowski, K., Morieri, G., Oldroyd, G. E. D., Downie, J. A., Nielsen, M. W., Rusek, A. M., Sato, S., Tabata, S., James, E. K., Oyaizu, H., Sandal, N., and Stougaard, J. 2009. Rearrangement of actin cytoskeleton mediates invasion of Lotus japonicus roots by Mesorhizobium loti. Plant Cell 21:267-284.

Zhang, Y., Zhang, F., and Huang, X. Z. 2019. Characterization of an Arabidopsis thaliana DUF761-containing protein with a potential role in development and defense responses. Theor. Exp. Plant Physiol. 31 303-316. 